\title{
Artificial Self-assembling Nanocompartment for Organizing Metabolic Pathways in Yeast
}

\author{
Li Chen Cheah, Terra Stark, Lachlan S. R. Adamson, Rufika S. Abidin, Yu Heng Lau, Frank Sainsbury,* \\ and Claudia E. Vickers*
}

Cite This: https://doi.org/10.1021/acssynbio.1c00045

Read Online

ACCESS

山ll Metrics \& More

回国 Article Recommendations

Supporting Information

ABSTRACT: Metabolic pathways are commonly organized by sequestration into discrete cellular compartments. Compartments prevent unfavorable interactions with other pathways and provide local environments conducive to the activity of encapsulated enzymes. Such compartments are also useful synthetic biology tools for examining enzyme/pathway behavior and for metabolic engineering. Here, we expand the intracellular compartmentalization toolbox for budding yeast (Saccharomyces cerevisiae) with Murine polyomavirus virus-like particles (MPyV VLPs). The MPyV system has two components: VP1 which self-assembles into the compartment shell and a short anchor, VP2C, which mediates cargo protein encapsulation via binding

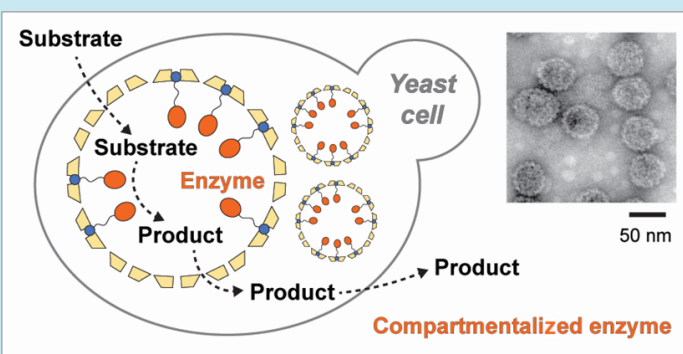
to the inner surface of the VP1 shell. Destabilized green fluorescent protein (GFP) fused to VP2C was specifically sorted into VLPs and thereby protected from host-mediated degradation. An engineered VP1 variant displayed improved cargo capture properties and differential subcellular localization compared to wild-type VP1. To demonstrate their ability to function as a metabolic compartment, MPyV VLPs were used to encapsulate myo-inositol oxygenase (MIOX), an unstable and rate-limiting enzyme in D-glucaric acid biosynthesis. Strains with encapsulated MIOX produced $20 \%$ more D-glucaric acid compared to controls expressing "free" MIOX-despite accumulating dramatically less expressed protein-and also grew to higher cell densities. This is the first demonstration in yeast of an artificial biocatalytic compartment that can participate in a metabolic pathway and establishes the $\mathrm{MPyV}$ platform as a promising synthetic biology tool for yeast engineering.

KEYWORDS: nanocompartment, polyomavirus, yeast, virus-like particles, glucaric acid, metabolic engineering

\section{INTRODUCTION}

Intracellular metabolic compartments are ubiquitous in nature. Common examples are the membrane-bound organelles, such as the mitochondrion, chloroplast, and peroxisome. In addition, certain prokaryotes express protein-based metabolic compartments, such as bacterial microcompartments (BMCs) and encapsulins. Compartments create discrete favorable environments for otherwise incompatible reactions, while minimizing unproductive interactions that lead to toxicity and metabolite loss. ${ }^{1,2}$ Other functions of compartments include spatially organizing successive enzymes in a pathway to improve pathway efficiency and increasing the local substrate concentration to favor a particular reaction. ${ }^{1,2}$ In some cases, engineered compartmentalization has been found to impart useful properties on enzymes such as improved activity and stability.

The bottom-up reconstruction of "synthetic organelles" has recently been explored using self-assembling protein compartments. ${ }^{4,5}$ These compartments can be used to encapsulate metabolic enzymes in an engineered pathway to enhance chemical bioproduction. The use of heterologous compartments reduces an undesirable cross-talk with the host cell metabolism and potentially enables a finer control of the reaction environment. Furthermore, the inherent programmability of protein-based compartments means their permeability and surface chemistry can be tuned to favor a particular reaction. For instance, the pore size and charge may be engineered to favor the influx of substrates and/or minimize the efflux of intermediate metabolites. ${ }^{6,7}$ As each type of protein compartment has characteristics that may make it better suited to different applications, it is useful to continually explore and develop new compartment platforms. One property that is particularly relevant for biocatalysis is its permeability to substrates-highly porous compartments such as the bacteriophage P22 procapsid permit free diffusion of small molecules, ${ }^{8}$ while compartments with small pores such as BMCs and encapsulins allow selective metabolite exchange. 90 Harnessing the natural diversity of self-assembling compart-

Received: February 1, 2021 
a

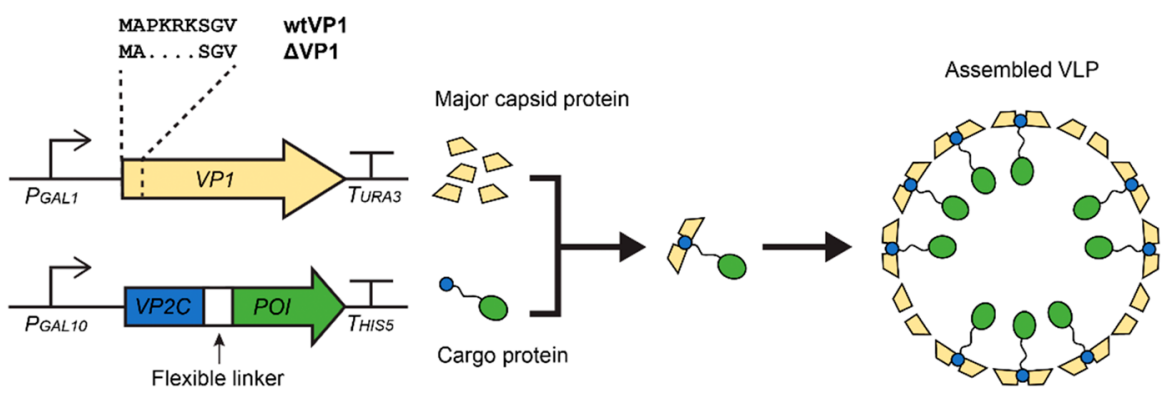

b
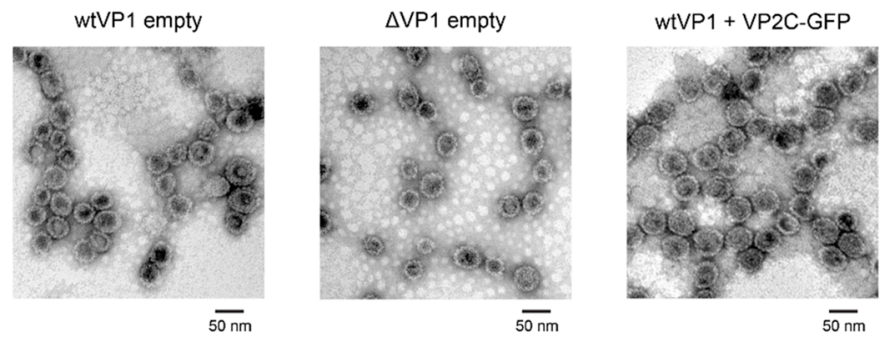

$\triangle \mathrm{VP} 1+\mathrm{VP} 2 \mathrm{C}-\mathrm{GFP}$

Figure 1. MPyV nanocompartment platform for yeast. (a) MPyV VLPs are formed by the self-assembly of two protein components, VP1 (wt or an NLS-deletion mutant, $\Delta$ ) and VP2C linked to the cargo protein of interest. (b) Transmission electron micrographs of purified VLPs expressed in the absence and presence VP2C- green fluorescent protein (GFP).

a

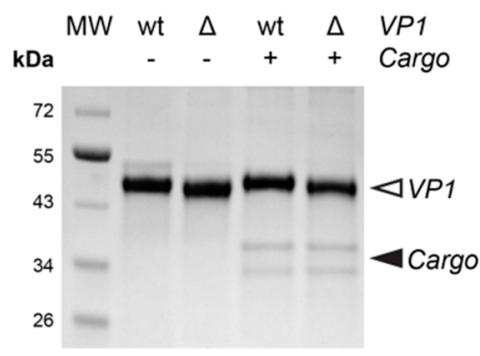

C

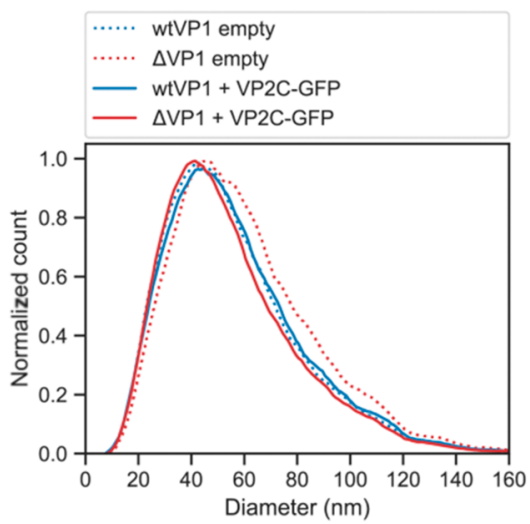

b

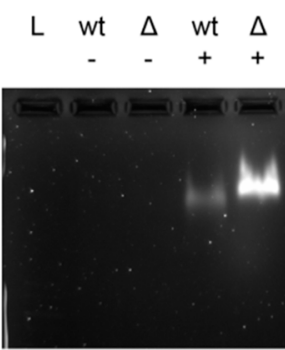

GFP
$\mathrm{L} \quad$ wt $\Delta$ wt $\Delta$

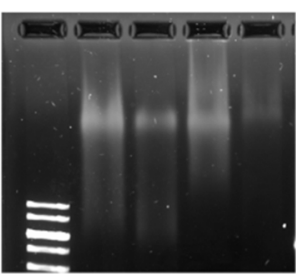

Nucleic acid
L wt $\triangle$ wt $\triangle \quad V P 1$

$-\quad+\quad+$ Cargo

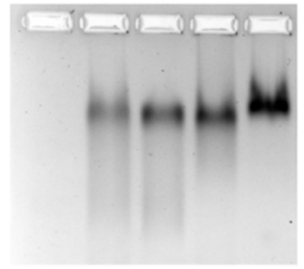

Protein d
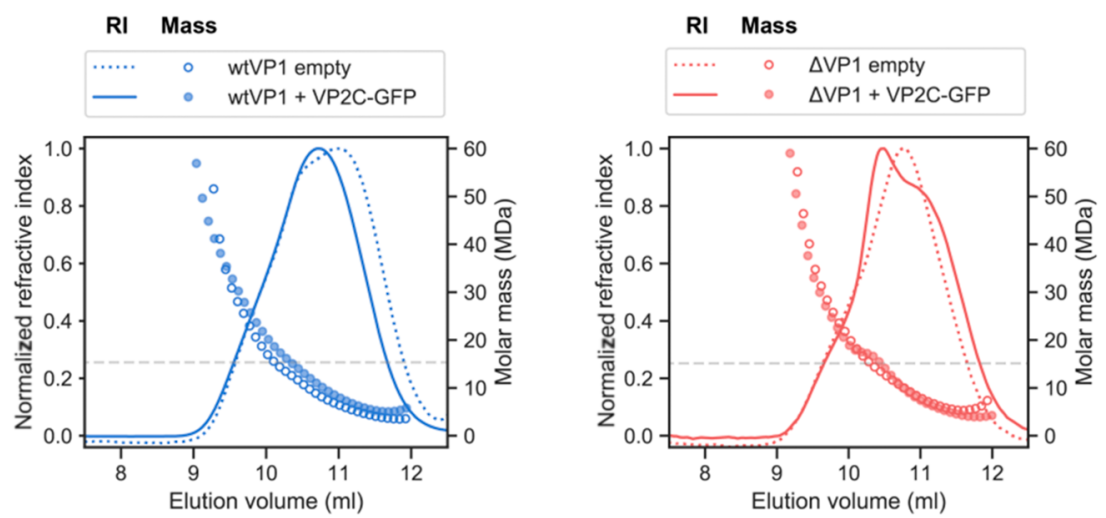

Figure 2. VLP characterization. (a) SDS-PAGE gel of purified VLP samples stained with Coomassie blue. Arrows show the position of VP1 and cargo bands. "MW" = protein molecular weight marker. (b) Native gel electrophoresis of purified particles. Samples ( $3 \mu \mathrm{g})$ were loaded on a $1 \%$ agarose gel alongside $0.5 \mu \mathrm{g}$ of a DNA molecular ladder (lane L). GFP signal from intact particles can be visualized with blue light illumination and a $530 \mathrm{~nm}$ emission filter. Nucleic acid and protein were stained with GelRed and Coomassie blue, respectively. The migration of assembled VLPs during native agarose gel electrophoresis is influenced by particle size and charge. Because VLP size distributions do not differ between constructs, the reduced migration of $\Delta \mathrm{VP} 1$ likely reflects the considerably reduced nucleic acid encapsulation. (c) Particle size distributions, measured with NTA. Data points are the means of two biological replicates. For clarity, error bars are not shown here; refer to Figure S4 for data with error bars and details on the analysis workflow. (d) Changes in size distribution and molar mass of wtVP1 and $\triangle$ VP1 VLPs with GFP loading, as determined by SEC-MALS. Refractive index, RI (normalized to the mode) is shown as lines and molar mass is shown as circles. Data from a representative run are shown. The dashed light gray line indicates the theoretical mass of empty VLPs corresponding to each VP1 variant (15.3 MDa for wtVP1 and 15.1 MDa for $\Delta \mathrm{VP} 1)$. 
ment structures thus allows us to generate a suite of tools that can fulfil distinct niches.

Here, we present an artificial metabolic nanocompartment for budding yeast (Saccharomyces cerevisiae) based on the Murine polyomavirus virus-like particle (MPyV VLP). MPyV coat proteins are known to self-assemble in various heterologous eukaryotic expression hosts, including yeasts. ${ }^{11-13}$ The MPyV VLP makes an attractive base for constructing designer compartments due to its amenability to engineering and ability to selectively package cargo proteins. ${ }^{14,15}$ The $\mathrm{MPyV}$ shell is porous, with gaps between capsomeres (virus assembly subunits) as well as a central $8.6 \AA$ pore through each capsomere; ${ }^{16,17}$ this could potentially enable access of encapsulated enzymes to small-molecule substrates. The VLP exterior can be functionalized with various domains by insertion into loop regions, a property which has previously been exploited for a modular antigen display. ${ }^{18-20}$ The compartment is $\sim 50 \mathrm{~nm}$ in diameter and has a theoretical maximum loading of 72 cargo proteins per particle, providing a larger capacity than a previously reported artificial nanocompartment system for yeast. ${ }^{21}$ By coat protein engineering, we developed an orthogonal compartment that is distributed throughout the cell and packages an exceptionally high density of cargo proteins. The MPyV platform was then applied toward the in vivo stabilization of a metabolic enzyme, which resulted in improved product titers as well as increased cell growth. The MPyV platform provides novel capabilities, expanding the in vivo protein scaffolding and compartmentalization toolbox for this important bioproduction chassis.

\section{RESULTS AND DISCUSSION}

Design and Characterization of a Synthetic MPyVBased Yeast Nanocompartment. The engineered MPyV system has two protein components: VP1, which forms the compartment shell, and VP2C, a short anchor for directing cargo protein encapsulation ${ }^{13,22}$ (Figure 1a). VP1 assembles into pentamers, which then further self-assembled into a VLP, nominally composed of 72 pentamers (360 VP1 monomers). Each VP1 pentamer can bind one VP2C anchor and, by extension, a cargo protein translationally fused to VP2C. Exploiting the VP2C-VP1 interaction allows the specific packaging of the cargo protein of interest during assembly of the VLP. Because VP2C is not essential for the pentamer or VLP formation, the assembled particles may contain variable numbers of "empty" pentamers, as depicted in Figure 1a.

When expressed in yeast, wild-type MPyV VP1 (wtVP1) forms VLPs in the nucleus. ${ }^{11}$ For this project, we were interested in designing a cytoplasmic compartment system because of the larger diversity of metabolic pathways and processes in the yeast cytoplasm compared to the nucleus. In our previous work on plant-expressed MPyV VLPs, ${ }^{13}$ the deletion of a putative nuclear localization signal on VP1 (mutant to be referred to as " $\triangle \mathrm{VP} 1$ " hereafter; Figure 1a) abolished exclusive nuclear localization while maintaining VLP assembly capabilities. We sought to assess the suitability of $\Delta \mathrm{VP1}$ for generating yeast compartments, comparing a localization, assembly, and capacity for cargo encapsulation with wtVP1 by first testing the system using yeast-enhanced $\mathrm{GFP}^{23}$ as the model cargo protein.

$\triangle \mathrm{VP1}$ and wtVP1 were expressed either alone (forming empty VLPs) or coexpressed with VP2C-GFP (forming GFPloaded VLPs) using strong galactose-inducible promoters (Figure 1a). Purified $\triangle \mathrm{VP1}$ and wtVP1 VLPs share a similar morphology under transmission electron microscopy (TEM) (Figure 1b). The expression of VP2C-GFP led to effective cargo packaging in both VLPs as indicated by sodium dodecyl sulfate-polyacrylamide gel electrophoresis (SDS-PAGE) (Figure 2a) and native agarose gel electrophoresis (Figure b). The cargo loading was estimated to be $\sim 59$ GFP per wtVP1 VLP and $\sim 72$ GFP per $\Delta$ VP1 VLP by SDS-PAGE densitometry. Samples encapsulating GFP always exhibited two cargo bands in SDS-PAGE. The identity of both visible cargo bands was verified by the anti-GFP Western blot (Figure $\mathrm{S} 1 \mathrm{a})$ and $\mathrm{N}$-terminal sequencing confirmed that the smaller cargo protein was a cleavage product of VP2C-GFP (Figure S1b). Using a pull-down assay in E. coli, we show that an even shorter truncation still allows binding to the VP1 pentamer (Figure S2), though it is not clear whether the degradation of the N-terminus occurs prior to, or after, VP1 binding. Nevertheless, no other bands were seen on SDS-PAGE other than that of VP1 and VP2C-GFP, confirming the specificity of VP2C-directed cargo packaging. Removal of the VP2C anchor led to VLPs with only very low levels of cargo protein (Figure S3), indicating that cargo loading did not occur by random "statistical" encapsulation.

Empty MPyV VLPs have been reported to non-specifically encapsulate genomic and plasmid DNA when expressed in yeast. ${ }^{11}$ Consistent with this, considerable nucleic acid staining for wtVP1 VLPs was observed on the native agarose gel (Figure 2b). Nucleic acid encapsulated in $\triangle$ VP1 VLPs was presumably RNA; however, it was greatly reduced compared to wtVP1, likely from the deletion of a number of positively charged residues in the mutation ${ }^{24,25}$ and, although we do not directly observe VLPs in vivo, shifting of the site of assembly away from the nucleus. ${ }^{26,27}$ Decreased nucleic acid encapsulation by $\triangle \mathrm{VP1}$ compared to wtVP1 has also been observed with plant-expressed MPyV VLPs. ${ }^{13}$ The minimization of nucleic acid encapsulation is desirable to maximize the effective capacity available for the compartmentalization of target proteins. The presence of encapsulated GFP also reduces nucleic acid capture for both wtVP1 and $\triangle \mathrm{VP} 1$. The protruding VP2C-GFP could presumably sterically "block" the lumen-facing surface of VP1 pentamers, reducing their availability for nucleic acid binding.

The four VLP variants exhibited very similar size distributions, as determined by nanoparticle tracking analysis (NTA) (Figure 2c). NTA is a sensitive imaging method that calculates the size of individual particles in the solution based on its Brownian motion. ${ }^{28}$ The peaks (modes) of the average distributions lie between $\sim 41$ and $46 \mathrm{~nm}$ and construct differences were indistinguishable from biological and technical variability (Figure S4). In a close agreement with NTA data, similar, overlapping size distributions were also observed by analytical size-exclusion chromatography (SEC) (Figure 2d). Therefore, the $\triangle \mathrm{VP} 1$ mutation and GFP packaging do not significantly impact the VLP size for yeast-assembled MPyV VLPs. Qualitative experiments on plant-assembled MPyV VLPs suggested a considerable impact of the $\triangle \mathrm{VP} 1$ mutation on particle size. ${ }^{13}$ With respect to cargo loading, previous findings for MPyV VLPs assembled in insect cells where coexpression with full-length VP2 resulted in fewer aberrantsized particles ${ }^{29}$ and a GFP cargo loading density-dependent decrease in size and heterogeneity was observed for in vitroassembled VLPs. ${ }^{22}$ Together, these results show that size and heterogeneity can depend on specific host cell factors and 
a

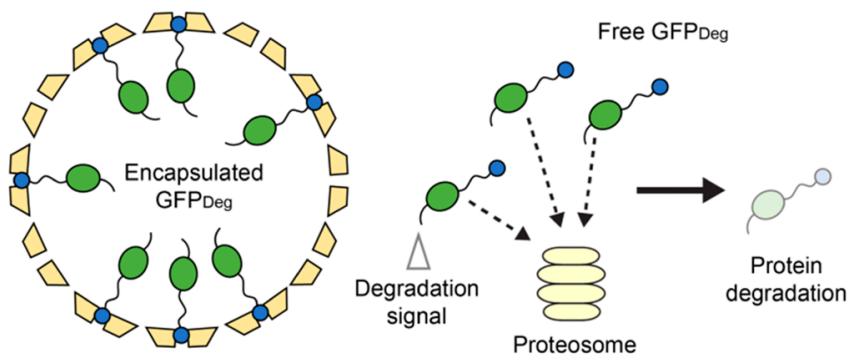

b

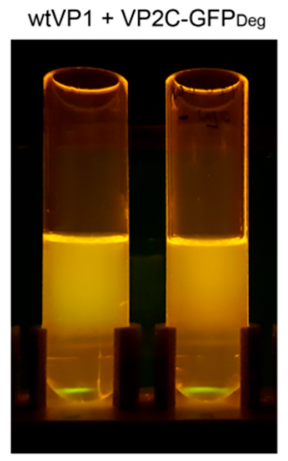

$\triangle$ VP1 + VP2C-GFPDeg

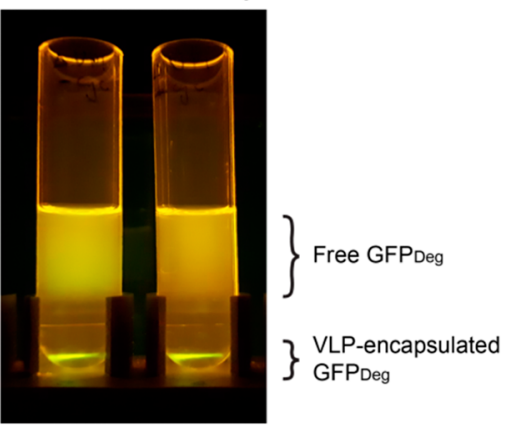

cycloheximide $c$

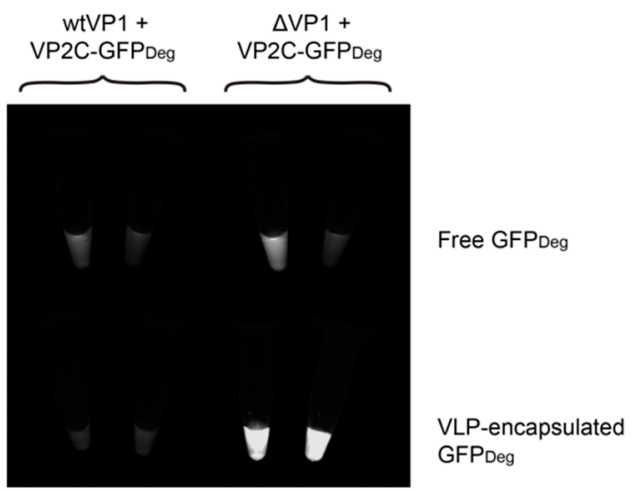

cycloheximide

Figure 3. Destabilized GFP as a model protein for assessing in vivo compartmentalization. (a) Tagging GFP with a degradation signal at the Cterminal $\left(\mathrm{GFP}_{\mathrm{Deg}}\right)$ targets it for proteasomal degradation, unless protected by VLP encapsulation. (b) Fluorescent lysates of VLP-expressing cells ultracentrifuged through an iodixanol cushion, with and without cycloheximide treatment. Substantial yeast autofluorescence can also be observed.

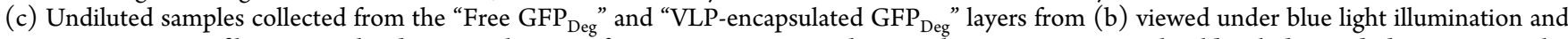
a $530 \mathrm{~nm}$ emission filter. Note that because ultracentrifugation concentrates the VLP layer, comparisons should only be made between samples from the same layer.
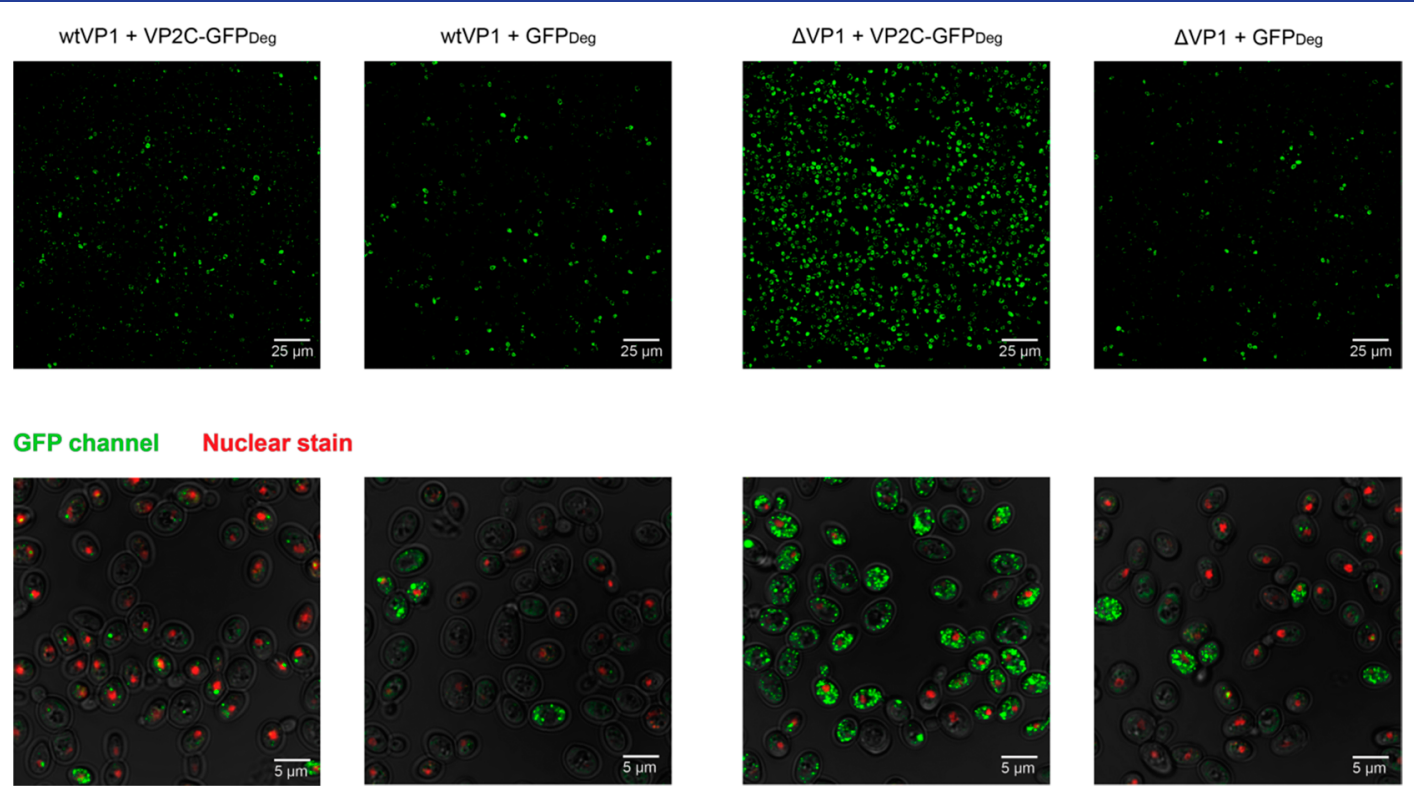

Figure 4. Visualizing compartment localization by confocal microscopy.

emphasize the importance of the ex vivo characterization of artificial nanocompartments.

Multiangle light scattering (MALS) of SEC elutions shows that the molar mass of purified VLPs had a broad distribution that was centered around $15 \mathrm{MDa}$, the theoretical mass of a 72-pentamer assembly (Figure 2d). The ability of $\mathrm{MPyV}$ to form assemblies of different sizes has previously been observed in vitro $^{22,30}$ and in vivo. ${ }^{13,31}$ Despite containing a high proportion of the cargo protein, the mass profiles of GFPloaded VLPs were overall not much different from that of empty VLPs; this is likely due to the additional nucleic acid in empty VLPs compensating for any differences in protein mass. Interestingly, the $\triangle \mathrm{VP} 1+\mathrm{VP} 2 \mathrm{C}-\mathrm{GFP}$ sample exhibits a pronounced mass "bump" around $10.2 \mathrm{~mL}$. Although this phenomenon remains to be investigated, it may indicate a bias 
a

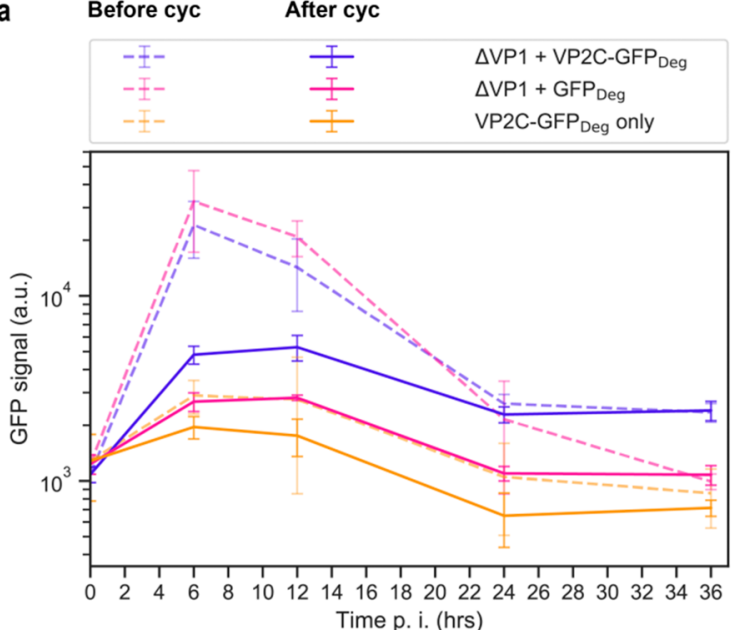

b

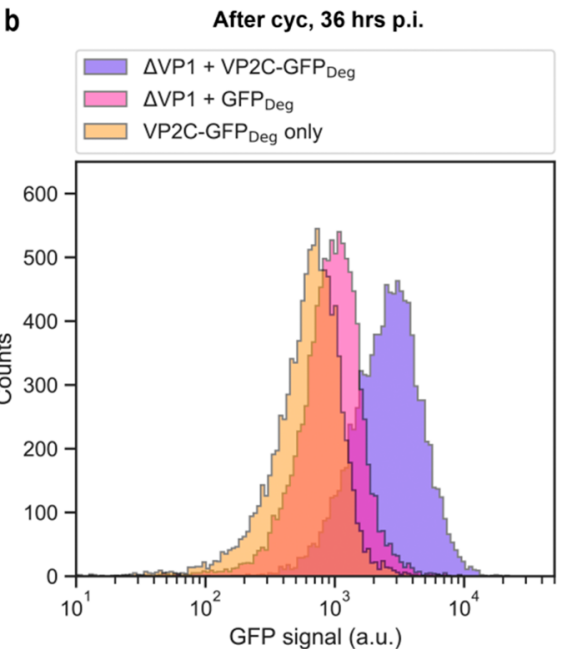

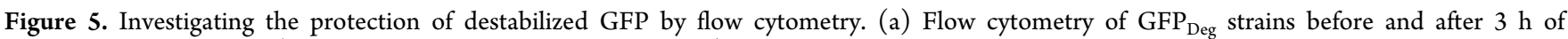
cycloheximide treatment ("before cyc" and "after cyc", respectively). The median was used to represent each sample of 10,000 cells. Values shown in the plot are the mean of three biological replicates, \pm 1 STD. (b) Sample raw flow cytometry histograms showing the population distribution for cycloheximide-treated cells at $36 \mathrm{~h}$ of post-induction.

in nucleic acid capture and cargo loading toward specific VLP sizes.

Removing the VP1 Nuclear Localization Signal Alters Compartment Localization and Improves Cargo Capture. VP2C-GFP is expected to diffuse freely through the yeast nuclear pore complex, ${ }^{32}$ making it a suitable reporter for the subcellular location of VP1 compartments. To distinguish encapsulated cargo from excess "free" cargo, we destabilized GFP by adding a C-terminal degradation signal from mouse ornithine decarboxylase. ${ }^{33}$ The resulting high-turnover report-

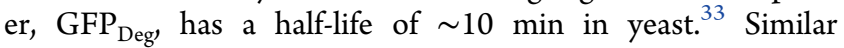
strategies have previously been applied to study other protein compartments in vivo ${ }^{21,34,35}$ and to target competing enzymes for metabolic engineering. ${ }^{36-38}$ The incubation of cultures with the protein synthesis inhibitor cycloheximide allows the "clearing" of unencapsulated cargo proteins, leaving only the signal from encapsulated $\mathrm{GFP}_{\text {Deg }}$ (Figure $3 \mathrm{a}$ ). This was verified by separating VLP-associated GFP ${ }_{\text {Deg }}$ from free $\mathrm{GFP}_{\text {Deg }}$ by the ultracentrifugation of whole cell lysates through an iodixanol cushion (Figure 3b). Even against an autofluorescent background, cycloheximide treatment led to a clear reduction in the fluorescence signal in the upper fraction (free proteins) but not the dense VLP fraction, demonstrating in vivo protection of $\mathrm{GFP}_{\text {Deg. }}$ Fusion to the VP2C anchor was required for the sedimentation of the $\mathrm{GFP}_{\text {Deg }}$ signal (Figure S3). Much greater levels of $\mathrm{GFP}_{\text {Deg }}$ were found to be VLP-associated in the $\triangle \mathrm{VP} 1$ strain compared to the wtVP1 strain (Figure 3c), an observation that was further confirmed by the dot blot (Figure S5).

To investigate subcellular localization in situ, cells were imaged by confocal laser scanning microscopy after $24 \mathrm{~h}$ of galactose induction and $3 \mathrm{~h}$ of cycloheximide treatment (Figure 4). The treatment duration was selected based on preliminary time-course experiments which showed that the residual GFP signal plateaus off $\sim 2 \mathrm{~h}$ after treatment (Figure S5). Each VP1 variant was coexpressed either with VP2C$\mathrm{GFP}_{\text {Deg }}$, or $\mathrm{GFP}_{\text {Deg }}$ as a control without directed GFP encapsulation. $\triangle \mathrm{VP1}$ compartments appear to be distributed throughout the cell while wtVP1 led to the formation of small, localized foci either adjacent to or co-localized with the DNA stain (Figure 4). This is consistent with a previous study on yeast-expressed wtVP1, where clusters of assembled VLPs were found to be associated with tubulin fibers in the nucleus. ${ }^{11}$ Importantly, it shows that the $\triangle \mathrm{VP} 1$ mutation also abolishes exclusive nuclear localization in yeast, thus facilitating access to a greater range of metabolites.

Cells expressing $\mathrm{GFP}_{\text {Deg }}$ are imaged after $24 \mathrm{~h}$ of galactose induction and $4 \mathrm{~h}$ of cycloheximide treatment. The top panel shows a wide field of view while the bottom panel is $5 \times$ zoomed relative to the top. The top panel shows only the GFP channel (colored green), while the bottom panel shows the merged images of the GFP, nuclear stain (colored red), and brightfield channels. The nuclear stain is Hoechst 34580, which is specific to dsDNA. The same imaging and processing parameters are used for all samples. To reduce autofluorescence, brightness and contrast for the GFP channel were adjusted until a minimal signal is visible in the untransformed negative control strain (Figure S6).

The higher intensity of the GFP fluorescence for $\Delta \mathrm{VP} 1+$ VP2C-GFP ${ }_{\text {Deg }}$ indicates that a higher proportion of expressed cargo proteins was captured and protected from degradation compared to wtVP1 $+\mathrm{VP} 2 \mathrm{C}-\mathrm{GFP}_{\text {Deg }}$ (Figures 4 and S6), consistent with ultracentrifugation observations (Figures $3 \mathrm{~b}$ and S5). Given that VP1 and VP2C-GFP expression levels were found to be similar for both variants (Figure S7), the efficiency of cargo capture represents the average cargo loading density as well as the total number of stable compartments per cell. Because the disparity in in vivo fluorescence is much greater than that of cargo loading density (Figure 2a,b), we infer that a higher proportion of expressed $\triangle \mathrm{VP} 1$ was able to successfully capture and protect VP2C-GFP ${ }_{\text {Deg }}$ compared to wtVP1. In contrast to a previous report showing that the $\mathrm{MPyV}$ wtVP1 overexpression in yeast leads to temporary growth inhibition $^{11}$ and despite being expressed with the strong GAL1 promoter, neither VP1 variant negatively impacted growth rates under the conditions tested (Figure S7). This is desirable because non-target physiological effects should be avoided both for examining basic biology and for applying synthetic biology tools in an industrial setting. 

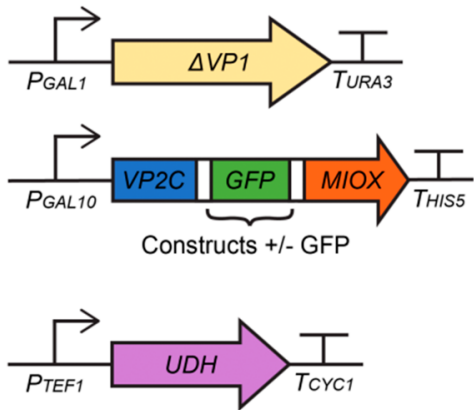

C

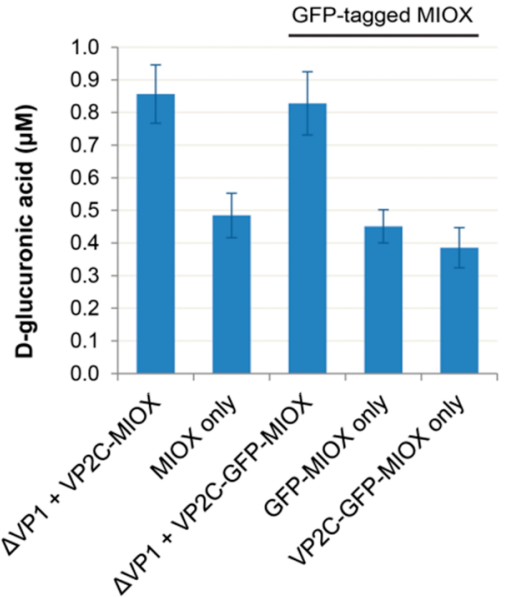

e

e

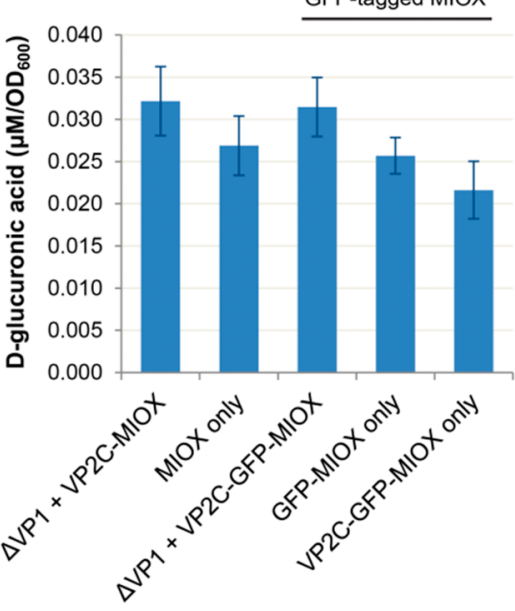

b
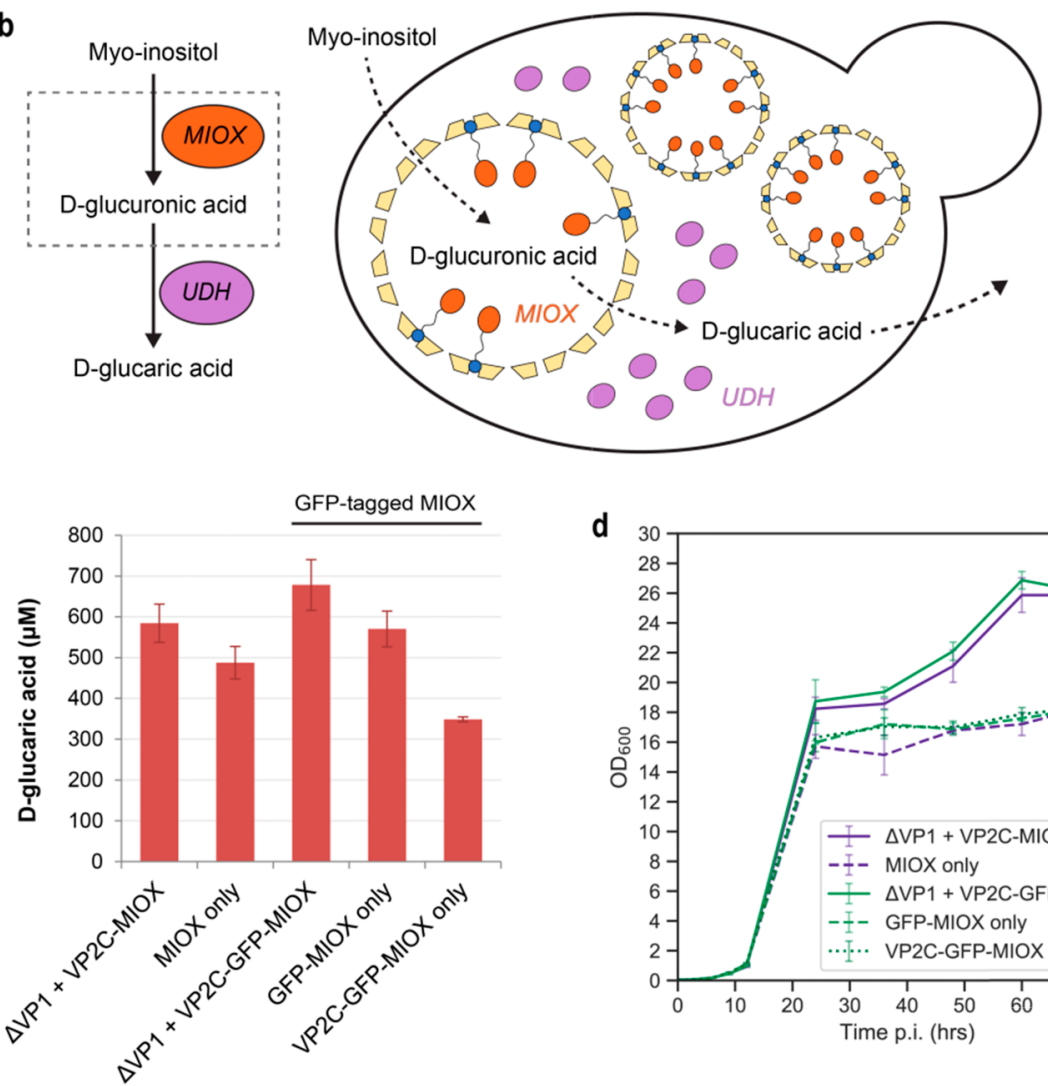

d

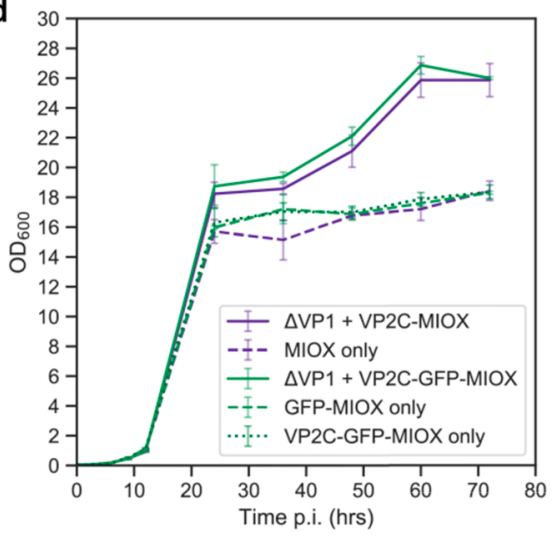

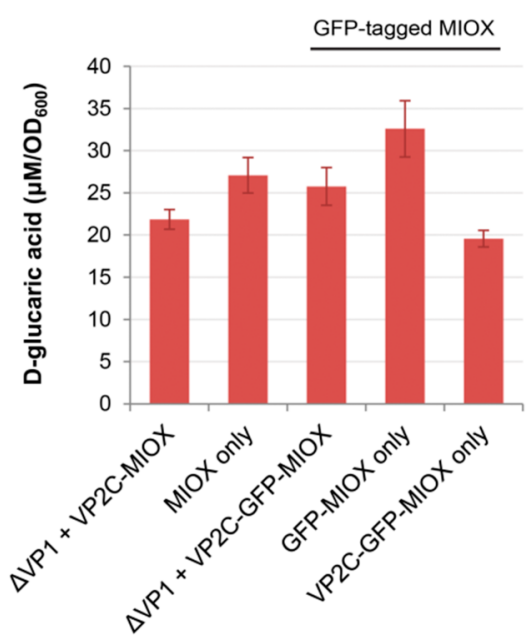

Figure 6. Compartmentalization of MIOX improved D-glucaric acid production. (a) Expression cassettes for MIOX encapsulation. Constructs were made with and without GFP as part of the cargo fusion protein. UDH is expressed using a strong constitutive promoter $\left(\mathrm{P}_{\mathrm{TEF} 1}\right)$. All genes were chromosomally integrated as a single copy. (b) Reaction schematic of the heterologous D-glucaric acid pathway and an illustration showing the proposed metabolite movements in the cell. The dashed gray box represents the compartment. Myo-inositol in the culture medium is taken up by yeast cells and diffuses into compartments. Encapsulated MIOX converts myo-inositol into D-glucuronic acid, which then diffuses out into the cytoplasm where it is further converted into D-glucaric acid by UDH. D-glucaric acid is then released into the culture medium. (c) Final titers of Dglucuronic acid and D-glucaric acid in the culture medium after $72 \mathrm{~h}$ of fermentation. (d) Cell density $\left(\mathrm{OD}_{600}\right)$ against time post-induction. (e) Product titers in (c), adjusted based on cell density. All data points are the means of three biological replicates; error bars are \pm 1 STD.

The confocal imaging indicated that there is a strong protective effect for encapsulated cargo. Flow cytometry was used to investigate this effect with an increasing induction time by tracking the level of $\mathrm{GFP}_{\text {Deg }}$ before and after cycloheximide treatment (Figure 5). We only characterized the $\Delta \mathrm{VP} 1$ variant because it exhibited preferred properties, namely, non-nuclear localization and better cargo protection. The $\mathrm{GFP}_{\text {Deg }}$ encapsulation strain $\left(\Delta \mathrm{VP} 1+\mathrm{VP} 2 \mathrm{C}-\mathrm{GFP}_{\mathrm{Deg}}\right)$ was compared with controls lacking either VP1 or the VP2C anchor. At every time point, the signal after cycloheximide treatment ("after cyc") of the GFP encapsulation strain was significantly higher than that of the controls, indicating the stabilization of a proportion of $\mathrm{GFP}_{\mathrm{Deg}}$ from degradation. The majority of cargo proteins were unencapsulated and not protected in the early induction phase $(<24 \mathrm{~h})$, as indicated by the large difference in the signal before and after cycloheximide treatment. As protein 
Table 1. S. cerevisiae Strains for D-Glucaric Acid Production ${ }^{a}$

\begin{tabular}{|c|c|c|}
\hline strain & genotype & reference \\
\hline CEN.PK2-1C & MATa ura3-52 leu2-3,112 trp1-289 his3 $\Delta 1$ MAL2-8c SUC2 & Entian and Kötter (2007)54 \\
\hline UDH only & CEN.PK2-1C derivative; leu2:: $\mathrm{T}_{\mathrm{CYC} 1}-\mathrm{UDH}-\mathrm{P}_{\mathrm{TEF} 1}-\mathrm{P}_{\mathrm{KILEU} 2}-\mathrm{KlLEU} 2$ & this work \\
\hline$\Delta \mathrm{VP} 1+\mathrm{VP} 2 \mathrm{C}-\mathrm{MIOX}$ & $\mathrm{UDH}$ only derivative; ura3::KlURA3- $\mathrm{T}_{\mathrm{HISS}}-(\mathrm{VP} 2 \mathrm{C}-\mathrm{MIOX})-\mathrm{P}_{\mathrm{GAL} 10}-\mathrm{P}_{\mathrm{GAL} 1}-\Delta \mathrm{VP} 1$ & this work \\
\hline MIOX only & UDH only derivative; ura3::KIURA3- $-\mathrm{T}_{\mathrm{HISS}}-\mathrm{MIOX}-\mathrm{P}_{\mathrm{GAL} 10}-\mathrm{P}_{\mathrm{GAL} 1}$ & this work \\
\hline$\Delta \mathrm{VP} 1+\mathrm{VP} 2 \mathrm{C}-\mathrm{GFP}-\mathrm{MIOX}$ & UDH only derivative; ura3::KlURA3- $\mathrm{T}_{\mathrm{HISS}}-(\mathrm{VP} 2 \mathrm{C}-\mathrm{GFP}-\mathrm{MIOX})-\mathrm{P}_{\mathrm{GAL} 10}-\mathrm{P}_{\mathrm{GALL}}-\Delta \mathrm{VP} 1$ & this work \\
\hline GFP-MIOX only & $\mathrm{UDH}$ only derivative; ura3::KIURA3- $\mathrm{T}_{\mathrm{HISS}}-(\mathrm{GFP}-\mathrm{MIOX})-\mathrm{P}_{\mathrm{GAL} 10}-\mathrm{P}_{\mathrm{GAL} 1}$ & this work \\
\hline VP2C-GFP-MIOX only & $\mathrm{UDH}$ only derivative; ura3::K1URA3- $\mathrm{T}_{\mathrm{HISS}}-(\mathrm{VP} 2 \mathrm{C}-\mathrm{GFP}-\mathrm{MIOX})-\mathrm{P}_{\mathrm{GAL} 10}-\mathrm{P}_{\mathrm{GAL} 1}$ & this work \\
\hline
\end{tabular}

synthesis slowed down, the proportion of encapsulated (and therefore, protected) $\mathrm{GFP}_{\text {Deg }}$ relative to total $\mathrm{GFP}_{\mathrm{Deg}}$ increased. After $24 \mathrm{~h}$, all $\mathrm{GFP}_{\text {Deg }}$ appears to be encapsulated for $\Delta \mathrm{VP} 1+\mathrm{VP} 2 \mathrm{C}-\mathrm{GFP}_{\mathrm{Deg}}$, while $\mathrm{GFP}_{\text {Deg }}$ depletion continued in the controls.

The difference in the signal between strains expressing $\mathrm{GFP}_{\text {Deg }}$ and VP2C-GFP $\mathrm{Geg}_{\text {in }}$ the absence of VP1 (Figures 5 and S5) suggests that VP2C itself also destabilizes the cargo protein prior to encapsulation. During the initial growth phase, the contributions of the induction level and protein stability to protein levels cannot be distinguished. However, preliminary experiments showed a faster signal depletion of $\triangle \mathrm{VP} 1+$ VP2C-GFP compared to $\triangle \mathrm{VP} 1+$ GFP after cycloheximide treatment, which would not be explained by differences in the induction level (Figure S5). During the prokaryotic expression, the $\mathrm{N}$-terminal fusion renders GFP insoluble; ${ }^{14}$ however, this is rescued by the VP1 co-expression as VP2C-VP1 binding masks the hydrophobic motif present on VP2C. ${ }^{22}$ Despite the reduced stability of VP2C-tagged GFP evident here in yeast, the effect of specific encapsulation led to a higher level of persistent $\mathrm{GFP}_{\text {Deg }}$ than the control lacking VP2C.

Artificial Compartmentalization as a Novel Enzyme Stabilization Strategy. After parameterizing the system, we next examined if enzymes encapsulated in vivo by $\mathrm{MPyV}$ remain functional and can participate in a bioproduction pathway. At the same time, we sought to explore a novel in vivo use for self-assembling protein compartments in metabolic engineering as a general purpose platform for stabilizing enzymes. We identified the cytoplasmic enzyme myo-inositol oxygenase (MIOX) as a suitable target for encapsulation due to its apparent instability when expressed in heterologous hosts. ${ }^{39,40}$ In both E. coli and S. cerevisiae, MIOX levels were found to rapidly decrease over the course of fermentation through an unknown mechanism. ${ }^{39,40}$ An artificial pathway has been described that only requires two enzymes to convert myo-inositol into D-glucaric acid, namely, Mus musculus MIOX and Pseudomonas syringae uronate dehydrogenase (UDH). ${ }^{39}$ This production pathway has previously been expressed and shown to be functional in S. cerevisiae. ${ }^{41} \mathrm{MIOX}$ is the ratelimiting enzyme of the pathway; subsequent engineering efforts for D-glucaric acid production have focused on improving its intracellular stability ${ }^{42}$ and expression level. ${ }^{40}$ Furthermore, mouse MIOX is a small, monomeric protein ${ }^{43}$ and appears to be generally tolerant to fusions at the $\mathrm{N}$ - and C-termini, ${ }^{42,44,45}$ which makes it an ideal candidate for exploring encapsulation within $\mathrm{MPyV}$ compartments via fusion to the self-sorting anchor, VP2C.

$\triangle \mathrm{VP1}$ and VP2C-MIOX were expressed using galactoseinducible promoters $\left(\mathrm{P}_{\mathrm{GAL} 1}\right.$ and $\left.\mathrm{P}_{\mathrm{GAL} 10}\right)$, while the second enzyme in the pathway, UDH, was expressed using the strong constitutive TEF1 promoter (Figure 6a, refer to Table 1 in the
Methods section for strain details). A set of constructs were also generated with GFP fused at the N-terminus of MIOX as a reporter for flow cytometry and Western blot. Altogether, five MIOX expression strategies were evaluated: $\triangle \mathrm{VP} 1+\mathrm{VP} 2 \mathrm{C}-$ MIOX (VLP-forming), MIOX only (free control), $\Delta \mathrm{VP} 1+$ VP2C-GFP-MIOX (VLP with GFP fusion), GFP-MIOX only (free control with GFP fusion), and VP2C-GFP-MIOX only (free control with a VP2C anchor and GFP fusion). All expression cassettes were integrated as single copies in the yeast genome to ensure stable and uniform gene expression. As per previous studies, ${ }^{40,41}$ myo-inositol was supplied directly in the culture medium and products were measured by sampling the culture medium (Figure $6 \mathrm{~b}$ ). Cultures were transferred from a glucose-containing medium to a galactose-containing medium upon flask inoculation, so the time of inoculation could be considered the point of $\triangle \mathrm{VP} 1$ and MIOX induction.

The D-glucuronic acid (intermediate) and D-glucaric acid (end product) titers in the culture medium were quantified by gas chromatography coupled to mass spectrometry (GC-MS) at $72 \mathrm{~h}$ (Figure 6c). S. cerevisiae is not known to harbor a native MIOX; confirming this, neither D-glucuronic acid nor Dglucaric acid was detected in the untransformed base strain (CEN.PK2-1C) or in the UDH-only strain (Figure S8). In MIOX-expressing strains, D-glucaric acid production ranged from 349 to $678 \mu \mathrm{M}$ and D-glucuronic acid from 0.39 to 0.86 $\mu \mathrm{M}$. The much lower concentration of $\mathrm{D}$-glucuronic acid detected compared to D-glucaric acid ( $\sim 3$ orders of magnitude difference) suggests that UDH activity is not limited in any of the strains and indicates that D-glucuronic acid produced by MIOX could readily escape MPyV compartments. The MPyV VLP has pores in the center of the capsomere of approximately $1 \mathrm{~nm}^{16,46}$ and although this may be partially occluded by VP2C binding, ${ }^{46}$ there are also spaces between capsomeres that may permit small-molecule diffusion. The effective permeability of $\mathrm{MPyV}$ VLPs remains to be tested empirically, using methods such as recently shown for bacteriophage P22 VLPs. ${ }^{47}$ The coexpression of $\triangle \mathrm{VP} 1$ with VP2C-GFP-MIOX almost doubled the final D-glucaric titer $(p<0.001)$ compared to VP2C-GFP-MIOX alone. Encapsulation strains (with or without GFP fusion) produced $\sim 20 \%$ more D-glucaric acid than their corresponding free MIOX controls without the destabilizing VP2C anchor; the increases were, however, not statistically significant $(p=0.053$ for MIOX pair and $p=0.070$ for GFP-MIOX pair, two-tailed Student's $t$-test) for the size of the data set used. Interestingly, the N-terminal fusion of GFP to free MIOX also increased D-glucaric acid productionpresumably by improving protein stability. This is in contrast to a previous E. coli study, ${ }^{42}$ where the fusion of MBP to the Nterminus of MIOX caused loss of in vivo enzyme activity.

The final cell densities of the two encapsulation strains were $>40 \%$ higher compared to the free MIOX controls (Figure 6d), 


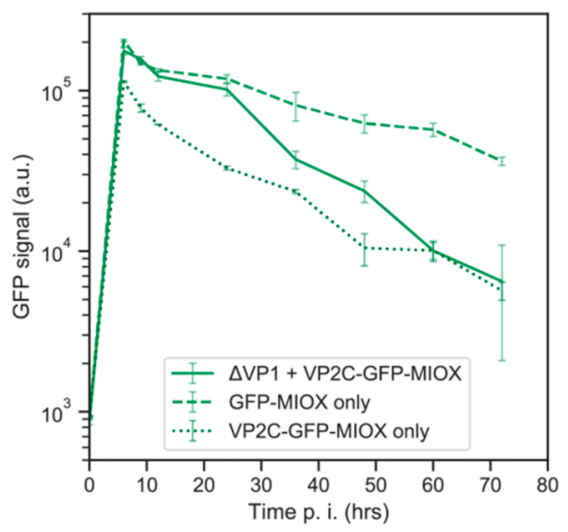

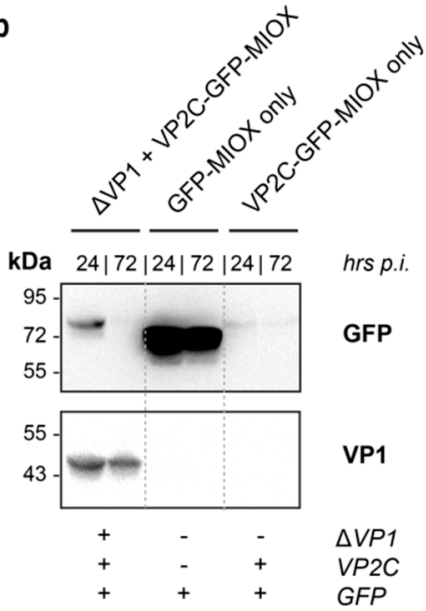

C

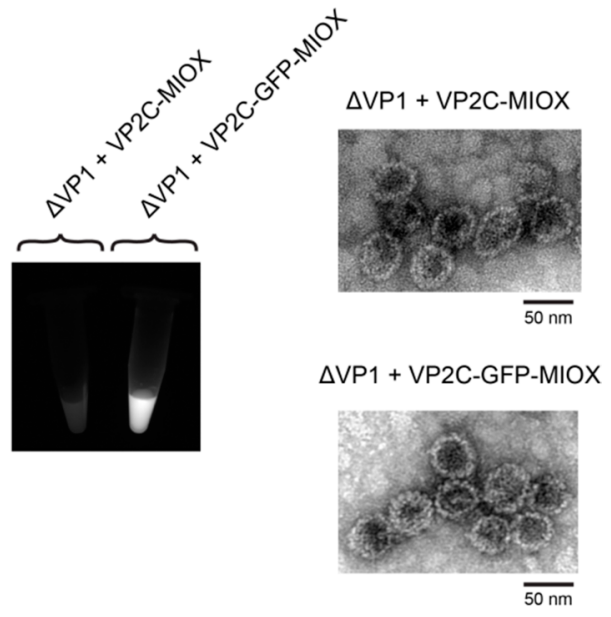

Figure 7. Protein expression levels of MIOX-expressing strains. (a) GFP fluorescence was tracked by flow cytometry as a proxy for MIOX levels in the three GFP-tagged MIOX constructs. (b) Anti-GFP and anti-VP1 western blots of cell lysates at 24 and $72 \mathrm{~h}$ of post-induction. The same amount of cells was loaded per lane, based on the $\mathrm{OD}_{600}$ reading. Bands on the anti-GFP blot match the expected size of each corresponding MIOX fusion protein. (c) MIOX compartments isolated by iodixanol cushion ultracentrifugation, diluted to $2 \mathrm{mg} / \mathrm{mL}$, and viewed under blue light illumination and a $530 \mathrm{~nm}$ emission filter. Compartment assembly was confirmed by negative-stain TEM. All data points in (a) are the means of three biological replicates; error bars are \pm 1 STD.

pointing to the mitigation of some form of metabolic burden by compartmentalization. This is an intriguing finding as neither myo-inositol nor D-glucaric acid were expected to be toxic at these concentrations: a previous yeast study found that extracellular concentrations of D-glucaric acid up to $5 \mathrm{~g} / \mathrm{L}$ (23.8 $\mathrm{mM}$ ) did not negatively affect strain growth or productivity; $^{41}$ similarly, they did not observe any difference in growth rates with or without the supplementation of myoinositol at the same concentration used here $(60 \mathrm{mM}){ }^{41}$ In contrast, the growth profiles of strains with encapsulated MIOX were similar to that of a non-MIOX-expressing control strain (Figure S9), suggesting that the overexpression of the MIOX protein may be inherently toxic to yeast. This is similar to a recent yeast study where the targeting of the norcoclaurine synthase into peroxisomes was found to alleviate cellular toxicity associated with the enzyme. ${ }^{48}$ Adjusting product titers by cell density, it is clear that the D-glucaric acid titer increase from MIOX compartmentalization was directly linked to the improved growth (Figure 6e).

The GFP signal detected by flow cytometry (Figure 7a) and Western blot (Figure 7b) was used as a proxy for intracellular MIOX levels in the three GFP-tagged strains. The GFPMIOX only strain had the most protein, followed by the $\Delta \mathrm{VP} 1$ + VP2C-GFP-MIOX and VP2C-GFP-MIOX only strains. Sorting into compartments clearly increased the stability of VP2C-GFP-MIOX; however, the destabilization effect of the VP2C anchor on cargo proteins was apparent-as observed earlier with $\mathrm{GFP}_{\text {Deg }}$ strains (Figure 5). Given the huge difference in the amount of GFP-MIOX in the GFP-MIOX only and $\Delta \mathrm{VP} 1+\mathrm{VP} 2 \mathrm{C}-\mathrm{GFP}-\mathrm{MIOX}$, the increase in Dglucaric acid titer for the encapsulation strain (Figure 6c) is quite remarkable. This result indicates a very strong stabilizing effect of encapsulation on MIOX activity, which may be similar to the stabilizing effect of encapsulation within protein cages observed for a number of enzymes. ${ }^{49,50}$ Despite protection by compartmentalization, VP2C-GFP-MIOX levels decreased after $24 \mathrm{~h}$ in the encapsulation strains. This may be due to the proportion of cargo (i.e., VP2C-GFP-MIOX) captured by VP1 being relatively small compared to the total expressed cargo, as also observed in the $\mathrm{GFP}_{\text {Deg }}$ experiments (Figure 5a).
Because active cell growth in the encapsulation strains continued beyond $24 \mathrm{~h}$ (after galactose would have been fully consumed), switching off of galactose-inducible promoters may have additionally "diluted" MIOX and $\triangle$ VP1 levels in the daughter cells to a greater degree compared to the other strains. VLP formation in $\triangle \mathrm{VP} 1$-expressing constructs was verified by TEM (Figure 7c) and VLPs isolated from $\triangle \mathrm{VP} 1+\mathrm{VP} 2 \mathrm{C}-\mathrm{GFP}-\mathrm{MIOX}$ were fluorescent green (Figure $7 \mathrm{c}$ ), confirming the presence of the cargo protein. Overall, the results show that the positive effect of MIOX encapsulation on growth and biomass accumulation was able to compensate for the reduced enzyme levels in terms of D-glucaric acid production.

\section{CONCLUSIONS}

We have established the engineered MPyV VLP system as a simple and orthogonal platform for protein compartmentalization in yeast. Implementation of the $\triangle \mathrm{VP} 1$ shell variant allowed specific and efficient compartmentalization of cytoplasmic cargo proteins. We then explored the compartmentalization of a naturally unstable metabolic enzyme, MIOX, for the bioproduction of D-glucaric acid. In contrast to previous in vivo studies which used protein compartments as a scaffold for co-localizing multiple enzymes in a reaction cascade, $^{4,5}$ we wanted to investigate if a pathway can be improved simply by encapsulating a single, rate-limiting enzyme. Strains with encapsulated MIOX successfully produced D-glucaric acid at higher titers than free MIOX. This is the first demonstration in yeast of a synthetic biocatalytic compartment that can participate in a metabolic pathway and shows that metabolites can diffuse through the $\mathrm{MPyV}$ shell. Moreover, an increased target product titer was achieved despite dramatically lower levels of the expressed protein. Compartment-forming strains grew to higher cell densities than the free controls, suggesting the alleviation of the metabolic burden from the MIOX expression. This work also provides proof-of-concept of using an orthogonal selfassembling protein compartment for protecting metabolic enzymes from in vivo degradation. 
To extend the work on D-glucaric acid production, it may be useful to investigate if deletion of the major inositol pathway regulator OPI1 could improve titers by increasing intracellular myo-inositol. ${ }^{40,41}$ Protein co-encapsulation with the MPyV compartment in yeast is the subject of an ongoing work. Another key direction for artificial in vivo metabolons such as MPyV VLPs will be to maximize the proportion of encapsulated cargo proteins. Our results show that encapsulation in self-assembling compartments is a promising strategy for isolating individual nodes in a reaction pathway and shielding proteins from specific interactions with host factors. Ultimately, we envision this self-assembling compartment as a versatile "plug-and-play" tool for studying and harnessing in vivo catalysis.

\section{METHODS}

Molecular Cloning and Strain Generation. All cloning was performed using the isothermal assembly method, using a NEBuilder HiFi DNA Assembly Master Mix (NEB \#E2621). $\triangle \mathrm{VP1}$ was codon-optimized for yeast and synthesized by GenScript. All other synthetic genes were manually codonoptimized for $S$. cerevisiae and synthesized as dsDNA fragments by Integrated DNA Technologies. First, the $\triangle \mathrm{VP1}$ empty plasmid was constructed by replacing the GFP sequence in pILGFPB5A $^{51}$ (YIp with a Kluyveromyces lactis URA3 marker) with a polymerase chain reaction (PCR)-amplified $\Delta \mathrm{VP} 1$. Then, the $\Delta \mathrm{VP} 1+\mathrm{VP} 2 \mathrm{C}-\mathrm{GFP}$ construct was generated by inserting PCR-amplified VP2C and GFP fragments between the $\mathrm{XbaI}$ and EcoRI sites of the $\triangle \mathrm{VP} 1$-only plasmid. All other constructs (except the UDH cassette) were made by replacing either $\triangle \mathrm{VP1}$ or VP2C-GFP of these two plasmids by restriction digest, gel purification, and isothermal assembly. PCR primer and synthetic gene sequences are listed in Tables S1 and S2, respectively. GFP was swapped for different cargo proteins $\left(\mathrm{GFP}_{\mathrm{Deg}}, \mathrm{MIOX}\right.$, and GFP-MIOX) by double digesting with BamHI and BglII. For control constructs without VP1, VP1 was excised by NotI and NheI (NEB) digestion and patched with a single-stranded DNA oligonucleotide. After incubating at $50{ }^{\circ} \mathrm{C}$ for $1 \mathrm{~h}$, each assembly reaction mix was directly transformed into chemically competent E. coli DH5 $\alpha$ by heat-shock. Plasmids purified from individual colonies were verified for the correct insert by Sanger sequencing (Australian Genome Research Facility). The $\mathrm{P}_{\mathrm{TEF} 1}-\mathrm{UDH}-\mathrm{T}_{\mathrm{CYC1}}$ expression cassette was generated over multiple assembly steps, starting with the pUG73 $3^{52}$ backbone vector which contains a $K$. lactis LEU2 marker.

For all constructs, the plasmids were first digested with SwaI (NEB \#R0604) and transformed using the LiAc/SS carrier DNA/PEG method, ${ }^{53}$ leading to stable single-copy integration into the yeast genome. The base strain is CEN.PK2-1C (MATa, his3D1, leu2-3_112, ura3-52, trp1-289, MAL2-8c, and SUC2 $)^{54}$ (Euroscarf). For the MIOX and UDH coexpression (Table 1), the base strain was first transformed with the $\mathrm{P}_{\mathrm{TEF} 1}-\mathrm{UDH}-\mathrm{T}_{\mathrm{CYC} 1}$ cassette (contains a leucine auxotrophic selection marker, LEU2). A single transformant was then used for the second transformation with MIOX expression cassettes. Yeast transformants were verified by colony PCR using the same primers used for cloning. Refer to Table S3 for the strain, plasmid, and protein part details. For every construct, at least three colonies recovered from yeast transformation were selected and maintained as biological replicates. Strains were grown overnight in YPD $(2 \% \mathrm{w} / \mathrm{v}$ Bacto peptone, $1 \% \mathrm{w} / \mathrm{v}$
Bacto yeast extract, and $2 \% \mathrm{w} / \mathrm{v}$ glucose) and stored as $20 \% \mathrm{v} /$ $\mathrm{v}$ glycerol stocks at $-80{ }^{\circ} \mathrm{C}$.

VLP Expression and Purification. All incubations were performed at $30{ }^{\circ} \mathrm{C}, 200 \mathrm{rpm}$ shaking (Infors HT Multitron incubator). Glycerol stocks were recovered on uracil drop-out agar plates and pre-cultured overnight in YPD. YPD cultures were diluted into YPGD (2\% w/v Bacto peptone, $1 \% \mathrm{w} / \mathrm{v}$ Bacto yeast extract, $2 \% \mathrm{w} / \mathrm{v}$ galactose, and $0.5 \% \mathrm{w} / \mathrm{v}$ glucose) at $\mathrm{OD}_{600}=0.2$ and grown for $24 \mathrm{~h}$. For VLP purification, we routinely grew $200-300 \mathrm{~mL}$ cultures in $500 \mathrm{~mL}$ unbaffled shake flasks. Cells were collected by centrifugation and stored at $-20{ }^{\circ} \mathrm{C}$ until required.

Thawed cell pellets were resuspended in lysis buffer $(20 \mathrm{mM}$ MOPS, $150 \mathrm{mM} \mathrm{NaCl}, 1 \mathrm{mM} \mathrm{CaCl} \mathrm{Cl}_{2}, 0.01 \%$ Triton X-100, pH 7.8) and lysed in three passes at $>22,000$ psi with a highpressure homogenizer (Avestin Emulsiflex C5). The PEG$\mathrm{NaCl}$ method $^{55}$ was used as a concentration and initial purification step. Briefly, $\mathrm{NaCl}$ and PEG 6000 were added to a final concentration of $0.5 \mathrm{M}$ and $8 \% \mathrm{w} / \mathrm{v}$, respectively (from a $5 \times \mathrm{PEG}-\mathrm{NaCl}$ stock). After storing overnight at $4{ }^{\circ} \mathrm{C}$, the precipitate was collected by centrifugation and resuspended in $2 \mathrm{~mL}$ of buffer A (20 mM MOPS, $150 \mathrm{mM} \mathrm{NaCl}, 1 \mathrm{mM}$ $\mathrm{CaCl}_{2}, \mathrm{pH} 7.8$ ). 1-2 mL PEG-concentrated sample or clarified lysate was layered onto a $1 \mathrm{~mL}$ cushion of $30 \%$ iodixanol (OptiPrep) in buffer A. Ultracentrifugation was run for $3 \mathrm{~h}$ at $100,000 g, 8{ }^{\circ} \mathrm{C}$ (Beckman Coulter Optima MAX-XP, TLA100.3 fixed-angle rotor). $100-200 \mu \mathrm{L}$ of the VLP sample was collected from the "dense" fraction at the bottom of each tube. Note: iodixanol absorbs strongly in the UV range and interferes with TEM negative staining-buffer exchange or sample dilution is advisable before further analysis.

The ultracentrifugation step isolates VLPs along with two high-MW yeast contaminants (Figure S10). An SEC step was used to polish samples and remove iodixanol. Samples were topped up to $1 \mathrm{~mL}$ with buffer $\mathrm{A}$ and loaded onto a HiPrep 16/60 Sephacryl S-500 HR column (GE Healthcare). Buffer A was run at $1 \mathrm{~mL} / \mathrm{min}$ and the flow-through was collected in 5 $\mathrm{mL}$ fractions. MPyV VLPs elute as a broad peak around 50-70 $\mathrm{mL}$ (Figure S10c). VLP fractions were pooled and concentrated using $100 \mathrm{kDa} \mathrm{MW}$ cutoff centrifugal filters (Amicon Ultra $4 \mathrm{~mL}$, Merck). Protein concentrations were measured using the linearized Bradford method ${ }^{56}$ with a Pierce Coomassie Protein Assay Kit (Thermo Scientific).

Gel Electrophoresis. $3 \mu \mathrm{g}$ of purified VLPs was loaded per lane. SDS-PAGE was run on Any $\mathrm{kD}$ Mini-PROTEAN TGX gels (Bio-Rad) in Tris-glycine SDS running buffer $(25 \mathrm{mM}$ Tris, $192 \mathrm{mM}$ glycine, $0.1 \% \mathrm{w} / \mathrm{v}$ SDS, $\mathrm{pH} 8.3$ ) at $150 \mathrm{~V}, 55$ min and stained with GelCode Blue Safe Protein Stain (Thermo Scientific \#24594). The protein MW marker used was Blue Prestained Protein Standard, Broad range (11-250 $\mathrm{kDa}$ ) (NEB \#P7718). Native gel electrophoresis of intact VLPs was run on a $1 \% \mathrm{w} / \mathrm{v}$ agarose mini gel $(7 \times 7 \mathrm{~cm})$ in TA buffer (40 mM Tris-base, $20 \mathrm{mM}$ acetic acid) at $90 \mathrm{~V}$ for $60 \mathrm{~min}$. VLP samples were suspended in buffer with bromophenol blue and $10 \% \mathrm{v} / \mathrm{v}$ glycerol (final concentration) to aid loading. EDTA was avoided in buffers as polyomavirus VLPs are known to be stabilized by interactions with calcium ions. ${ }^{30,57}$ Nucleic acid staining was performed by soaking the gel in $1 \times$ GelRed (Biotium \#41003) in TA buffer for $1 \mathrm{~h}$ at room temperature, with gentle shaking. $0.5 \mu \mathrm{g}$ of DNA ladder (Thermo Scientific \#SM0311) was loaded as a positive control. For visualizing proteins, gels were stained with GelCode Blue Safe Protein Stain (Thermo Scientific \#24594) overnight. Images were 
captured with a ChemiDoc MP Imaging System (Bio-Rad). Imaging settings: "fluorescein" preset (blue epi excitation, 530/ $30 \mathrm{~nm}$ filter) for GFP fluorescence, "ethidium bromide" preset (UV excitation, 605/50 nm filter) for stained nucleic acid, and "coomassie blue" preset for the protein.

Transmission Electron Microscopy (TEM). VLP samples were diluted in phosphate buffered saline (PBS) or buffer A to $\sim 0.1 \mathrm{mg} / \mathrm{mL}$ and settled on formvar/carbon coated copper mesh grids (ProSciTech \#GSCU200C) for 1-2 min. Grids were briefly rinsed in a drop of distilled water (excess removed with filter paper) and stained with $1 \% \mathrm{w} / \mathrm{v}$ aqueous uranyl acetate for $1 \mathrm{~min}$. Uranyl acetate was then blotted off with filter paper and the grids air-dried for a few minutes before storing. Grids were imaged with a Hitachi HT7700 transmission electron microscope at $80 \mathrm{kV}$ (High Contrast mode).

Nanoparticle Tracking Analysis (NTA). VLP samples were diluted $\sim 100 \mathrm{ng} / \mathrm{mL}$ in buffer $\mathrm{A}$ and analyzed with a NanoSight NS300 (Malvern Panalytical) equipped with a 405 $\mathrm{nm}$ laser and temperature control. The syringe pump speed during capture was set at 100 and $3 \times 60$ s videos were recorded for each sample. Optimal particle concentration was 50-100 particles/frame; if required, samples were diluted further and re-analyzed until the captured data fall within the acceptable range. Imaging settings: camera level $=15$, temperature $=25.0{ }^{\circ} \mathrm{C}$, viscosity $=1.0 \mathrm{cP}$, detect threshold $=$ 5. Raw particle data were exported from acquisition software (NTA 3.3 Dev Build 3.3.104) for further analysis.

Analytical Size-exclusion Chromatography. Separations were performed with a Shimadzu Prominence XR HPLC with a Nexera Bio Kit connected to MALS (Wyatt Dawn 8) and UV-vis absorbance (Shimadzu SPD-M20A photodiode array) detectors. Purified VLP samples were diluted to $0.1-0.2 \mathrm{mg} / \mathrm{mL}$ in PBS and filtered with $0.22 \mu \mathrm{m}$ cellulose acetate spin-filters (Sigma-Aldrich \#CLS8161). $25 \mu \mathrm{L}$ of each sample was injected through a Bio SEC-5 $2000 \AA$ HPLC column (Agilent) with a Bio SEC-5,2000 ̊ guard (Agilent). The mobile phase was PBS, with a constant flow rate of $1 \mathrm{~mL} / \mathrm{min}$ for a $20 \mathrm{~min}$ run. The laser wavelength for MALS was $659 \mathrm{~nm}$. The molar mass was fitted based on a Zimm light scattering model using Wyatt ASTRA 7 software.

Ultracentrifugation Analysis. YPD overnight precultures were diluted into $50 \mathrm{~mL}$ of YPG at $\mathrm{OD}_{600}=0.4$ and grown for $6 \mathrm{~h}$ at $30{ }^{\circ} \mathrm{C}, 200 \mathrm{rpm}$ shaking. Cycloheximide was added to $100 \mu \mathrm{g} / \mathrm{mL}$ and cultures were returned to an incubator for a further $3 \mathrm{~h}$ to allow sufficient degradation of the unencapsulated cargo protein. Cells were collected by centrifugation. The same amount of cells for each sample was transferred to $2 \mathrm{~mL}$ screw-capped tube, adjusting based on the $\mathrm{OD}_{600}$ value. The samples were resuspended to $1 \mathrm{~mL}$ total volume in lysis buffer and vortexed with $\sim 0.5 \mathrm{~g}$ of $0.5 \mathrm{mM}$ glass beads on a tabletop vortex mixer with a microtube rack. Six cycles of 1 min vortex $+1 \mathrm{~min}$ on ice were performed. Debris was removed by centrifugation at $12,000 \mathrm{~g}$ for $5 \mathrm{~min}$. The clarified lysate was layered onto a $1 \mathrm{~mL}$ cushion of $30 \%$ iodixanol (OptiPrep) in buffer $\mathrm{A}$ in clear ultracentrifuge tubes $(3.5 \mathrm{~mL}$ thickwall polycarbonate tubes, Beckman Coulter \#349622). Ultracentrifugation was run for $3 \mathrm{~h}$ at 100,000g, $8{ }^{\circ} \mathrm{C}$ (Beckman Coulter Optima MAX-XP, TLA-100.3 fixed-angle rotor). Ultracentrifuge tubes were photographed through an orange filter, backlit with a blue light transilluminator (Safe Imager 2.0, Invitrogen). $200 \mu \mathrm{L}$ of samples were collected from the top "free $\mathrm{GFP}_{\text {Deg }}$ " and dense "VLP-encapsulated $\mathrm{GFP}_{\text {Deg }}$ " layers into clear $1.5 \mathrm{~mL}$ microcentrifuge tubes. All tubes were imaged simultaneously with a ChemiDoc MP Imaging System (Bio-Rad) using the "fluorescein" preset (blue epi excitation, $530 / 30 \mathrm{~nm}$ filter).

Flow Cytometry. YPD overnight pre-cultures were diluted 1:100 into $3 \mathrm{~mL}$ of YPG (2\% w/v Bacto peptone, $1 \% \mathrm{w} / \mathrm{v}$ Bacto yeast extract, $2 \% \mathrm{w} / \mathrm{v}$ galactose) in 24-well culture plates and grown at $30{ }^{\circ} \mathrm{C}, 200 \mathrm{rpm}$ shaking. Flow cytometry was performed on live cells immediately after sampling using an Accuri C6 Flow Cytometer (BD Biosciences). At every time point, $500 \mu \mathrm{L}$ culture was also transferred into a separate well containing cycloheximide (final concentration $100 \mu \mathrm{g} / \mathrm{mL}$ ). Cultures with cycloheximide were returned to an incubator for further $3 \mathrm{~h}$ before flow cytometry. The GFP signal was measured using $488 \mathrm{~nm}$ laser excitation and a 533/30 nm BP emission filter. 10,000 cells were sampled for each reading (trigger threshold FSC-H > 250,000). Each biological replicate is a separate colony recovered during yeast transformation.

Confocal Microscopy. YPD overnight pre-cultures were diluted into YPG at $\mathrm{OD}_{600}=0.2$ and grown for $24 \mathrm{~h}$ at $30{ }^{\circ} \mathrm{C}$, $200 \mathrm{rpm}$ shaking. Cycloheximide was added to a final concentration of $100 \mu \mathrm{g} / \mathrm{mL}$ and cultures were returned to an incubator for a further $3 \mathrm{~h}$ to allow the sufficient degradation of the unencapsulated cargo protein. Cells were harvested by gentle centrifugation, washed once with PBS, and fixed with $4 \% \mathrm{w} / \mathrm{v}$ methanol-free formaldehyde (Thermo Scientific \#28906) for $20 \mathrm{~min}$ at room temperature. Nuclear staining was performed by incubating cells with $10 \mu \mathrm{g} / \mathrm{mL}$ Hoechst 34580 (Invitrogen \#H21486) for $30 \mathrm{~min}$ at room temperature. Cells were immobilized on glass-bottom dishes (Cellvis \#D35C4-20-1.5-N) pre-coated with $0.1 \mathrm{mg} / \mathrm{mL}$ concanavalin-A (Sigma-Aldrich \#C2010). Images were taken with an Olympus FV3000 confocal laser scanning microscope with a $60 \times$ silicone oil immersion objective (1.3 NA) using the "EGFP" and "Hoechst 33342" filter presets. Cells were focused using the Hoechst channel to minimize GFP photobleaching. Image brightness and contrast were adjusted using ImageJ and were kept consistent across the whole sample set. The untransformed base strain (CEN.PK2-1C) was used as a control for cell autofluorescence (see Figure S6).

Western Blot. The amount loaded per lane was normalized by $\mathrm{OD}_{600}$ readings (equivalent to $10 \mu \mathrm{L}$ of culture at $\mathrm{OD}_{600}=$ 20). The samples were run on Any $\mathrm{kD}$ Mini-PROTEAN TGX gels (Bio-Rad) in Tris-glycine-SDS buffer at $150 \mathrm{~V}, 55 \mathrm{~min}$, and transferred onto nitrocellulose membranes (Amersham Protran $0.45 \mu \mathrm{m}$, GE Healthcare) by wet transfer at $75 \mathrm{~V}, 60$ min. The transfer buffer was $1 \times$ SDS-PAGE buffer $+20 \% \mathrm{v} / \mathrm{v}$ methanol. Even protein transfer was verified by staining the membrane with $0.1 \% \mathrm{w} / \mathrm{v}$ Ponceau $\mathrm{S}$ in $5 \% \mathrm{v} / \mathrm{v}$ acetic acid. Membranes were blocked with $5 \% \mathrm{w} / \mathrm{v}$ skim milk in PBS + $0.05 \% \mathrm{v} / \mathrm{v}$ Tween 20 for $>1 \mathrm{~h}$ at RT and incubated with primary antibodies overnight at $4{ }^{\circ} \mathrm{C}$. Membranes were washed briefly with blocking buffer and incubated with secondary antibodies for $90 \mathrm{~min}$ at RT. The antibodies and dilutions used were as follows: rabbit anti-VP1 antiserum 1:2000, mouse antiGFP monoclonal IgG (Cell Signaling Technology \#2955) 1:2000; anti-rabbit IgG-HRP (Cell Signaling Technology \#7074) 1:2000, anti-mouse IgG-HRP (Cell Signaling Technology \#7076) 1:2000. Rabbit anti-VP1 antiserum was produced by Walter and Eliza Hall Institute Antibody Services using wtVP1 expressed in E. coli and assembled into VLPs in vitro. $^{18}$ Blots were visualized with a Clarity Western ECL Substrate (Bio-Rad \#1705060) and imaged with a ChemiDoc MP Imaging System (Bio-Rad). 
Fermentation for D-Glucaric Acid Production. Glycerol stocks were recovered on uracil drop-out plates and precultured overnight in YPD. Cultures were inoculated to $\mathrm{OD}_{600}$ $=0.05$ in $20 \mathrm{~mL}$ of YPG $+60 \mathrm{mM}$ myo-inositol, in $50 \mathrm{~mL}$ unbaffled shake flasks. "Time post-induction" was counted from the time of inoculation. Cultures were grown at $30{ }^{\circ} \mathrm{C}$ with $200 \mathrm{rpm}$ shaking. At every time point, cultures were sampled for $\mathrm{OD}_{600}$ and flow cytometry measurements. Culture samples for Western blot and GC-MS were stored at $-20{ }^{\circ} \mathrm{C}$ until further use.

Metabolite Analysis by GC-MS. Frozen cultures were thawed completely and centrifuged to pellet cells and debris. $200 \mu \mathrm{L}$ of each sample supernatant (culture medium) was evaporated to dryness with a rotational vacuum concentrator (Concentrator Plus, Eppendorf). The samples were derivatized with $20 \mu \mathrm{L}$ of methoxyamine ( $30 \mathrm{mg} / \mathrm{mL}$ in pyridine) for 60 min at $37{ }^{\circ} \mathrm{C}$ with mixing at $900 \mathrm{rpm}$, followed by trimethylsilylation with $30 \mu \mathrm{L}$ of $\mathrm{N}, \mathrm{O}$-bis(trimethylsilyl)trifluoroacetamide $+1 \%$ trimethylchlorosilane for $45 \mathrm{~min}$ at $50{ }^{\circ} \mathrm{C}$ with mixing at $900 \mathrm{rpm}$. Analytical standards (dissolved in distilled water) were derivatized the same way as the samples. The standards used were D-saccharic acid (D-glucaric acid) potassium salt $>98 \%$ (Sigma-Aldrich \#S4140) and Dglucuronic acid >98\% (Sigma-Aldrich \#G5269).

Analyses were performed on an Agilent 7890A gas chromatograph coupled to an Agilent 5975C quadrupole mass spectrometer (Agilent Technologies, Santa Clara, CA) with a Gerstel Autosampler (MPS 2 XL). Gas chromatography was performed using a $30 \mathrm{~m} \mathrm{~J} \& W$ VF-5 ms GC column with $10 \mathrm{~m}$ EZ-Guard (Agilent Technologies, Santa Clara, CA). Helium was used as the carrier gas at a constant flow rate of 1 $\mathrm{mL} / \mathrm{min}$. The $\mathrm{GC}$ oven temperature was started at $120{ }^{\circ} \mathrm{C}$ and held for $1 \mathrm{~min}$, then ramped to $230^{\circ} \mathrm{C}$ at $8{ }^{\circ} \mathrm{C} / \mathrm{min}$, and finally to $300{ }^{\circ} \mathrm{C}$ at $20{ }^{\circ} \mathrm{C} / \mathrm{min} .1 \mu \mathrm{L}$ of the derivatized sample was injected in the split mode with a split ratio of 20:1. A mass spectrometer scanned over the range of $50-500 \mathrm{~m} / z$, maintaining the temperature of the mass detector at $150{ }^{\circ} \mathrm{C}$, the transfer line at $200{ }^{\circ} \mathrm{C}$, while the ion source was kept at $230{ }^{\circ} \mathrm{C}$.

Glucuronic acid and glucaric acid were detected in the positive electron impact mode at $70 \mathrm{eV}$ using the standard autotune procedure for mass calibration. Acquisition was performed in total ion chromatography for identification and in selected ion monitoring for quantitation purposesmonitoring $\mathrm{m} / \mathrm{z}$ signals at $114,160,364 \mathrm{Da}$ (glucuronic acid) 292, 305, and $333 \mathrm{Da}$ (glucaric acid) with a dwell time of $100 \mathrm{~ms}$ for each signal. Data were processed using Enhanced ChemStation software and Agilent MassHunter Quantitative Analysis B.10.00 (Agilent Technologies, Santa Clara, CA). Microsoft Excel was used for further analysis and data plotting.

Data Analysis. Data analysis and plotting for NTA, SECMALS, $\mathrm{OD}_{600}$, and flow cytometry were performed with Python 3. Graphs were generated using the Matplotlib package. Each NTA data set consisted of two independent biological replicates, and each sample contains $3 \times 60$ s NTA video captures (refer to Figure S4 for an illustration of the analysis workflow). The data from each $60 \mathrm{~s}$ capture were individually plotted as histograms of binwidth $=1 \mathrm{~nm}$, smoothed with a Savitzky-Golay filter (savgol_filter from the scipy.signal package), and normalized to the highest count. Savitzky-Golay filter parameters: window size $=21$, polynomial order $=3$, mode $=$ "constant". The three histograms were then averaged to produce the datapoints for that sample. The final data set shows the mean of the two replicate samples. For flow cytometry, raw flow cytometry data (.fcs files) were analyzed with the FlowCal package. The median of each population of 10,000 cells (calculated using FlowCal) is used to represent each biological replicate. The mean and standard deviation of the three median values were then calculated to generate the final data points.

\section{ASSOCIATED CONTENT}

\section{SI Supporting Information}

The Supporting Information is available free of charge at https://pubs.acs.org/doi/10.1021/acssynbio.1c00045.

Supplementary figures referenced in the main text (Figures S1-S10); PCR primer, synthetic gene, and strain details (Tables S1-S3). Plasmids used in this work are available from Addgene: wtVP1 empty \#166673, wtVP1 + VP2C-GFP \#166674, $\Delta$ VP1 empty \#166675, $\Delta \mathrm{VP} 1+\mathrm{VP} 2 \mathrm{C}-\mathrm{GFP} \# 166676, \Delta \mathrm{VP} 1+\mathrm{VP}_{2 \mathrm{CGFP}}$ \#166677, wtVP1 + VP2C-GFP ${ }_{\text {Deg, }} \mathrm{P}_{\mathrm{TEF} 1}-\mathrm{UDH}-\mathrm{T}_{\mathrm{CYC} 1}$ \#166679, $\Delta$ VP1 + VP2C-MIOX \#166680, MIOX only \#166681, $\Delta$ VP1 + VP2C-MIOX \#166682. (PDF)

\section{AUTHOR INFORMATION}

\section{Corresponding Authors}

Frank Sainsbury - Australian Institute for Bioengineering and Nanotechnology, The University of Queensland, St Lucia, Queensland 4072, Australia; CSIRO Future Science Platform in Synthetic Biology, Commonwealth Scientific and Industrial Research Organisation (CSIRO), Dutton Park, Queensland 4102, Australia; Centre for Cell Factories and Biopolymers, Griffith Institute for Drug Discovery, Griffith University, Nathan, Queensland 4111, Australia; (1) orcid.org/00000001-8152-3820; Email: f.sainsbury@griffith.edu.au

Claudia E. Vickers - Australian Institute for Bioengineering and Nanotechnology, The University of Queensland, St Lucia, Queensland 4072, Australia; CSIRO Future Science Platform in Synthetic Biology, Commonwealth Scientific and Industrial Research Organisation (CSIRO), Dutton Park, Queensland 4102, Australia; Centre for Cell Factories and Biopolymers, Griffith Institute for Drug Discovery, Griffith University, Nathan, Queensland 4111, Australia; ARC Centre of Excellence in Synthetic Biology, Queensland University of Technology, Brisbane City, Queensland 4000, Australia; (1) orcid.org/0000-0002-0792-050X;

Email: Claudia.Vickers@csiro.au

\section{Authors}

Li Chen Cheah - Australian Institute for Bioengineering and Nanotechnology, The University of Queensland, St Lucia, Queensland 4072, Australia; CSIRO Future Science Platform in Synthetic Biology, Commonwealth Scientific and Industrial Research Organisation (CSIRO), Dutton Park, Queensland 4102, Australia

Terra Stark - Metabolomics Australia (Queensland Node), The University of Queensland, St Lucia, Queensland 4072, Australia

Lachlan S. R. Adamson - School of Chemistry, The University of Sydney, Camperdown, New South Wales 2006, Australia

Rufika S. Abidin - Australian Institute for Bioengineering and Nanotechnology, The University of Queensland, St Lucia, Queensland 4072, Australia 
Yu Heng Lau - School of Chemistry, The University of Sydney, Camperdown, New South Wales 2006, Australia; (1) orcid.org/0000-0001-6560-8410

Complete contact information is available at: https://pubs.acs.org/10.1021/acssynbio.1c00045

\section{Author Contributions}

C.E.V. and F.S. conceived and supervised the project. L.C.C. designed and conducted experiments. T.S. performed metabolite analysis by GC-MS. L.S.R.A. and Y.H.L. performed SEC-MALS experiments. R.S.R.A. provided supporting E. coli data. L.C.C., F.S., and C.E.V. wrote the manuscript

\section{Notes}

The authors declare no competing financial interest.

\section{ACKNOWLEDGMENTS}

This work was supported in part by a Research Grant from the Human Frontier Science Program (ref.no: RGP0012/2018). L.C.C. is supported by a Commonwealth Research Training Program scholarship. Additional funding for this project was provided through a Commonwealth Scientific and Industrial Research Organization (CSIRO) Synbio PhD Top-up Scholarship. F.S. acknowledges support from CSIRO in the form of a Synthetic Biology Future Science Platform Fellowship. The authors thank Donna McNeale (Griffith University) for preparing purified wtVP1 for raising VP1 antiserum and Mitchell O'Sullivan (Queensland University of Technology) for assistance with writing Python scripts for data analysis. The authors acknowledge the Translational Research Institute Australia (TRI) for providing the Microscopy Core Facility that enabled this research and thank Adler Ju for confocal microscopy technical assistance. The authors acknowledge the facilities, and the scientific and technical assistance, of the Microscopy Australia Facility at the Centre for Microscopy and Microanalysis (CMM), The University of Queensland. Aspects of this research have been facilitated by access to Metabolomics Australia and the Australian Proteome Analysis Facility, supported under the Australian Government's National Collaborative Research Infrastructure Strategy (NCRIS).

\section{REFERENCES}

(1) Lee, H.; DeLoache, W. C.; Dueber, J. E. Spatial Organization of Enzymes for Metabolic Engineering. Metab. Eng. 2012, 14, 242-51.

(2) Polka, J. K.; Hays, S. G.; Silver, P. A. Building Spatial Synthetic Biology with Compartments, Scaffolds, and Communities. Cold Spring Harbor Perspect. Biol. 2016, 8, a024018.

(3) Küchler, A.; Yoshimoto, M.; Luginbühl, S.; Mavelli, F.; Walde, P. Enzymatic Reactions in Confined Environments. Nat. Nanotechnol. 2016, 11, 409-420.

(4) Giessen, T. W.; Silver, P. A. A Catalytic Nanoreactor Based on in Vivo Encapsulation of Multiple Enzymes in an Engineered Protein Nanocompartment. ChemBioChem 2016, 17, 1931-1935.

(5) Lawrence, A. D.; Frank, S.; Newnham, S.; Lee, M. J.; Brown, I. R.; Xue, W.-F.; Rowe, M. L.; Mulvihill, D. P.; Prentice, M. B.; Howard, M. J.; Warren, M. J. Solution Structure of a Bacterial Microcompartment Targeting Peptide and Its Application in the Construction of an Ethanol Bioreactor. ACS Synth. Biol. 2014, 3, 454-465.

(6) Glasgow, J. E.; Asensio, M. A.; Jakobson, C. M.; Francis, M. B.; Tullman-Ercek, D. Influence of Electrostatics on Small Molecule Flux through a Protein Nanoreactor. ACS Synth. Biol. 2015, 4, 1011-1019.

(7) Williams, E. M.; Jung, S. M.; Coffman, J. L.; Lutz, S. Pore Engineering for Enhanced Mass Transport in Encapsulin Nanocompartments. ACS Synth. Biol. 2018, 7, 2514-2517.
(8) Sharma, J.; Uchida, M.; Miettinen, H. M.; Douglas, T. Modular Interior Loading and Exterior Decoration of a Virus-like Particle. Nanoscale 2017, 9, 10420-10430.

(9) Chowdhury, C.; Chun, S.; Pang, A.; Sawaya, M. R.; Sinha, S.; Yeates, T. O.; Bobik, T. A. Selective Molecular Transport through the Protein Shell of a Bacterial Microcompartment Organelle. Proc. Natl. Acad. Sci. U.S.A. 2015, 112, 2990-2995.

(10) Putri, R. M.; Allende-Ballestero, C.; Luque, D.; Klem, R.; Rousou, K.-A.; Liu, A.; Traulsen, C. H.-H.; Rurup, W. F.; Koay, M. S. T.; Castón, J. R.; Cornelissen, J. J. L. M. Structural Characterization of Native and Modified Encapsulins as Nanoplatforms for in Vitro Catalysis and Cellular Uptake. ACS Nano 2017, 11, 12796-12804.

(11) Palková, Z.; Adamec, T.; Liebl, D.; Štokrová, J.; Forstová, J. Production of Polyomavirus Structural Protein VP1 in Yeast Cells and Its Interaction with Cell Structures. FEBS Lett. 2000, 478, 281-289.

(12) Simon, C.; Klose, T.; Herbst, S.; Han, B. G.; Sinz, A.; Glaeser, R. M.; Stubbs, M. T.; Lilie, H. Disulfide Linkage and Structure of Highly Stable Yeast-Derived Virus-like Particles of Murine Polyomavirus. J. Biol. Chem. 2014, 289, 10411-10418.

(13) Catrice, E. V. B.; Sainsbury, F. Assembly and Purification of Polyomavirus-Like Particles from Plants. Mol. Biotechnol. 2015, 57, 904-913.

(14) Abbing, A.; Blaschke, U. K.; Grein, S.; Kretschmar, M.; Stark, C. M. B.; Thies, M. J. W.; Walter, J.; Weigand, M.; Woith, D. C.; Hess, J.; Reiser, C. O. A. Efficient Intracellular Delivery of a Protein and a Low Molecular Weight Substance via Recombinant Polyomavirus-like Particles. J. Biol. Chem. 2004, 279, 27410-27421.

(15) Inoue, T.; Kawano, M. A.; Takahashi, R. U.; Tsukamoto, H.; Enomoto, T.; Imai, T.; Kataoka, K.; Handa, H. Engineering of SV40Based Nano-Capsules for Delivery of Heterologous Proteins as Fusions with the Minor Capsid Proteins VP2/3. J. Biotechnol. 2008, 134, 181-92.

(16) Nelson, C. D. S.; Ströh, L. J.; Gee, G. V.; O’Hara, B. A.; Stehle, T.; Atwood, W. J. Modulation of a Pore in the Capsid of JC Polyomavirus Reduces Infectivity and Prevents Exposure of the Minor Capsid Proteins. J. Virol. 2015, 89, 3910-3921.

(17) Stehle, T.; Yan, Y.; Benjamin, T. L.; Harrison, S. C. Structure of Murine Polyomavirus Complexed with an Oligosaccharide Receptor Fragment. Nature 1994, 369, 160-163.

(18) Middelberg, A. P. J.; Rivera-Hernandez, T.; Wibowo, N.; Lua, L. H. L.; Fan, Y.; Magor, G.; Chang, C.; Chuan, Y. P.; Good, M. F.; Batzloff, M. R. A Microbial Platform for Rapid and Low-Cost Viruslike Particle and Capsomere Vaccines. Vaccine 2011, 29, 7154-7162.

(19) Tekewe, A.; Fan, Y.; Tan, E.; Middelberg, A. P. J.; Lua, L. H. L. Integrated Molecular and Bioprocess Engineering for Bacterially Produced Immunogenic Modular Virus-like Particle Vaccine Displaying $18 \mathrm{KDa}$ Rotavirus Antigen. Biotechnol. Bioeng. 2017, 114, 397406.

(20) Takahashi, R.-u.; Kanesashi, S.-n.; Inoue, T.; Enomoto, T.; Kawano, M.-a.; Tsukamoto, H.; Takeshita, F.; Imai, T.; Ochiya, T.; Kataoka, K.; Yamaguchi, Y.; Handa, H. Presentation of Functional Foreign Peptides on the Surface of SV40 Virus-like Particles. J. Biotechnol. 2008, 135, 385-392.

(21) Lau, Y. H.; Giessen, T. W.; Altenburg, W. J.; Silver, P. A. Prokaryotic Nanocompartments Form Synthetic Organelles in a Eukaryote. Nat. Commun. 2018, 9, 1311.

(22) Dashti, N. H.; Abidin, R. S.; Sainsbury, F. Programmable In Vitro Coencapsidation of Guest Proteins for Intracellular Delivery by Virus-like Particles. ACS Nano 2018, 12, 4615-4623.

(23) Cormack, B. P.; Bertram, G.; Egerton, M.; Gow, N. A. R.; Falkow, S.; Brown, A. J. P. Yeast-Enhanced Green Fluorescent Protein (YEGFP): A Reporter of Gene Expression in Candida Albicans. Microbiology 1997, 143, 303-311.

(24) Moreland, R. B.; Montross, L.; Garcea, R. L. Characterization of the DNA-Binding Properties of the Polyomavirus Capsid Protein VP1. J. Virol. 1991, 65, 1168-1176.

(25) Chang, D.; Cai, X.; Consigli, R. A. Characterization of the DNA binding properties of polyomavirus capsid protein. J. Virol. 1993, 67, 6327-6331. 
(26) Moreland, R. B.; Garcea, R. L. Characterization of a Nuclear Localization Sequence in the Polyomavirus Capsid Protein VP1. Virology 1991, 185, 513-518.

(27) Chang, D.; Haynes, J. I.; Brady, J. N.; Consigli, R. A. The Use of Additive and Subtractive Approaches to Examine the Nuclear Localization Sequence of the Polyomavirus Major Capsid Protein VP1. Virology 1992, 189, 821-827.

(28) Anderson, W.; Kozak, D.; Coleman, V. A.; Jämting, Å. K.; Trau, M. A Comparative Study of Submicron Particle Sizing Platforms: Accuracy, Precision and Resolution Analysis of Polydisperse Particle Size Distributions. J. Colloid Interface Sci. 2013, 405, 322-330.

(29) Lipin, D. I.; Chuan, Y. P.; Lua, L. H. L.; Middelberg, A. P. J. Encapsulation of DNA and Non-Viral Protein Changes the Structure of Murine Polyomavirus Virus-like Particles. Arch. Virol. 2008, 153, 2027-2039.

(30) Salunke, D. M.; Caspar, D. L.; Garcea, R. L. Polymorphism in the Assembly of Polyomavirus Capsid Protein VP1. Biophys. J. 1989, 56, 887-900.

(31) Sasnauskas, K.; Bulavaite, A.; Hale, A.; Jin, L.; Knowles, W. A.; Gedvilaite, A.; Dargeviciūte, A.; Bartkeviciūte, D.; Žvirbliene, A.; Staniulis, J.; Brown, D. W.; Ulrich, R. Generation of Recombinant Virus-like Particles of Human and Non-Human Polyomaviruses in Yeast Saccharomyces Cerevisiae. Intervirology 2002, 45, 308-17.

(32) Timney, B. L.; Raveh, B.; Mironska, R.; Trivedi, J. M.; Kim, S. J.; Russel, D.; Wente, S. R.; Sali, A.; Rout, M. P. Simple Rules for Passive Diffusion through the Nuclear Pore Complex. J. Cell Biol. 2016, 215, 57-76.

(33) Hoyt, M. A.; Zhang, M.; Coffino, P. Ubiquitin-Independent Mechanisms of Mouse Ornithine Decarboxylase Degradation Are Conserved between Mammalian and Fungal Cells. J. Biol. Chem. 2003, 278, 12135-12143.

(34) Kim, E. Y.; Tullman-Ercek, D. A Rapid Flow Cytometry Assay for the Relative Quantification of Protein Encapsulation into Bacterial Microcompartments. Biotechnol. J. 2014, 9, 348-354.

(35) Quin, M. B.; Perdue, S. A.; Hsu, S.-Y.; Schmidt-Dannert, C. Encapsulation of Multiple Cargo Proteins within Recombinant Eut Nanocompartments. Appl. Microbiol. Biotechnol. 2016, 100, 91879200.

(36) Peng, B.; Plan, M. R.; Chrysanthopoulos, P.; Hodson, M. P.; Nielsen, L. K.; Vickers, C. E. A Squalene Synthase Protein Degradation Method for Improved Sesquiterpene Production in Saccharomyces Cerevisiae. Metab. Eng. 2017, 39, 209-219.

(37) Peng, B.; Nielsen, L. K.; Kampranis, S. C.; Vickers, C. E. Engineered Protein Degradation of Farnesyl Pyrophosphate Synthase Is an Effective Regulatory Mechanism to Increase Monoterpene Production in Saccharomyces Cerevisiae. Metab. Eng. 2018, 47, 8393.

(38) Lu, Z.; Peng, B.; Ebert, B. E.; Dumsday, G.; Vickers, C. E. Auxin-Mediated Protein Depletion for Metabolic Engineering in Terpene-Producing Yeast. Nat. Commun. 2021, 12, 1051.

(39) Moon, T. S.; Yoon, S.-H.; Lanza, A. M.; Roy-Mayhew, J. D.; Prather, K. L. J. Production of Glucaric Acid from a Synthetic Pathway in Recombinant Escherichia Coli. Appl. Environ. Microbiol. 2009, 75, 589-595.

(40) Chen, N.; Wang, J.; Zhao, Y.; Deng, Y. Metabolic Engineering of Saccharomyces Cerevisiae for Efficient Production of Glucaric Acid at High Titer. Microb. Cell Factories 2018, 17, 67.

(41) Gupta, A.; Hicks, M. A.; Manchester, S. P.; Prather, K. L. J. Porting the synthetic D-glucaric acid pathway from Escherichia coli to Saccharomyces cerevisiae. Biotechnol. J. 2016, 11, 1201-1208.

(42) Shiue, E.; Prather, K. L. J. Improving D-Glucaric Acid Production from Myo-Inositol in E. Coli by Increasing MIOX Stability and Myo-Inositol Transport. Metab. Eng. 2014, 22, 22-31.

(43) Brown, P. M.; Caradoc-Davies, T. T.; Dickson, J. M. J.; Cooper, G. J. S.; Loomes, K. M.; Baker, E. N. Crystal Structure of a Substrate Complex of Myo-Inositol Oxygenase, a Di-Iron Oxygenase with a Key Role in Inositol Metabolism. Proc. Natl. Acad. Sci. U.S.A. 2006, 103, 15032-15037.
(44) Dueber, J. E.; Wu, G. C.; Malmirchegini, G. R.; Moon, T. S.; Petzold, C. J.; Ullal, A. V.; Prather, K. L.; Keasling, J. D. Synthetic Protein Scaffolds Provide Modular Control over Metabolic Flux. Nat. Biotechnol. 2009, 27, 753.

(45) Liu, Y.; Gong, X.; Wang, C.; Du, G.; Chen, J.; Kang, Z. Production of Glucaric Acid from Myo-Inositol in Engineered Pichia Pastoris. Enzyme Microb. Technol. 2016, 91, 8-16.

(46) Chen, X. S.; Stehle, T.; Harrison, S. C. Interaction of Polyomavirus Internal Protein VP2 with the Major Capsid Protein VP1 and Implications for Participation of VP2 in Viral Entry. EMBO J. 1998, 17, 3233-3240.

(47) Selivanovitch, E.; LaFrance, B.; Douglas, T. Molecular Exclusion Limits for Diffusion across a Porous Capsid. Nat. Commun. 2021, 12, 2903.

(48) Grewal, P. S.; Samson, J. A.; Baker, J. J.; Choi, B.; Dueber, J. E. Peroxisome Compartmentalization of a Toxic Enzyme Improves Alkaloid Production. Nat. Chem. Biol. 2021, 17, 96-103.

(49) Das, S.; Zhao, L.; Elofson, K.; Finn, M. G. Enzyme Stabilization by Virus-Like Particles. Biochemistry 2020, 59, 2870-2881.

(50) Wang, Y.; Uchida, M.; Waghwani, H. K.; Douglas, T. Synthetic Virus-like Particles for Glutathione Biosynthesis. ACS Synth. Biol. 2020, 9, 3298-3310.

(51) Peng, B.; Williams, T. C.; Henry, M.; Nielsen, L. K.; Vickers, C. E. Controlling Heterologous Gene Expression in Yeast Cell Factories on Different Carbon Substrates and across the Diauxic Shift: A Comparison of Yeast Promoter Activities. Microb. Cell Factories 2015, $14,91$.

(52) Gueldener, U.; Heinisch, J.; Koehler, G. J.; Voss, D.; Hegemann, J. H. A Second Set of LoxP Marker Cassettes for CreMediated Multiple Gene Knockouts in Budding Yeast. Nucleic Acids Res. 2002, 30, No. e23.

(53) Gietz, R. D. Yeast Transformation by the LiAc/SS Carrier DNA/PEG Method. In Methods in Molecular Biology: Yeast Protocols, Springer, 2014; Vol. 1163, pp 257-271.

(54) Entian, K.-D.; Kötter, P. 25 Yeast Genetic Strain and Plasmid Collections. Methods Microbiol. 2007, 36, 629-666.

(55) Friedmann, T.; Haas, M. Rapid Concentration and Purification of Polyoma Virus and SV40 with Polyethylene Glycol. Virology 1970, 42, 248-250.

(56) Ernst, O.; Zor, T. Linearization of the Bradford Protein Assay. J. Visualized Exp. 2010, 38, 1918.

(57) Adamec, T.; Palková, Z.; Velková, K.; Stokrová, J.; Forstová, J. Point mutation in calcium-binding domain of mouse polyomavirus VP1 protein does not prevent virus-like particle formation, but changes VP1 interactions with Saccharomyces cerevisiae cell structures. FEMS Yeast Res. 2005, 5, 331-40. 